\title{
Incentivos à corrupção e à inação no serviço público: Uma análise de desenho de mecanismos
}

\author{
Mauricio Bugarin \\ Professor - Universidade de Brasília (UnB) \\ Endereço: Prédio da FACE, Sala AT 85/87 - Campus Darcy Ribeiro - Brasília/DF \\ CEP: 70910-900 - E-mail: bugarin.mauricio@gmail.com
}

Fernando B. Meneguin

Consultor Legislativo -Senado Federal - Consultoria Legislativa/Gabinete 6

Endereço: Praça dos Três Poderes - Brasília/DF

CEP: 70165-900 - E-mail: fbmeneguin@hotmail.com

Recebido em 29 de maio de 2013. Aceito em 02 de outubro de 2015.

\section{Resumo}

O artigo analisa os incentivos criados pelo marco legal brasileiro ao desempenho e à gestão inovadora no funcionalismo público. Um modelo de teoria da decisão sugere que servidores de carreira tendem a não inovar em sua gestão para não serem acusados de comportamento ilícito, dado o Princípio Constitucional da Legalidade. Já gestores temporários em cargos comissionados tendem a ser mais inovadores, resultando em benefício para a sociedade, no caso dos gestores com elevada consciência social, ou malefício, no caso de gestores que se corrompem. Um estudo econométrico preliminar em painéis envolvendo os ministérios de 2002 a 2013 sugere haver maior evidência de corrupção em ministérios com maior percentual de cargos de confiança ocupados por gestores temporários. Uma análise de desenho de mecanismos indica como o marco institucional pode ser alterado de forma a alinhar os incentivos dos gestores, induzindo a inovação geradora de bem-estar social e reduzindo a corrupção.

\section{Palavras-Chave}

Gestão pública. Princípio constitucional da legalidade. Princípio constitucional da eficiência. Gestão inovadora. Corrupção.

\begin{abstract}
The present paper analyzes the institutional incentives public managers face in Brazil. A decision-theoretic model suggests that the constitutional principle of "Legality" induces tenured civil servants to adopt a non-innovative, bureaucratic management. On the other hand, temporary appointed managers tend to be more active, which could either generate higher social returns, in the case of socially inclined managers, or lower social return, in the case of managers involved in corrupt activities. A preliminary panel

- Duas versões anteriores deste trabalho receberam o Prêmio Tesouro Nacional de Finanças Públicas (ESAF, 2012) e o Edgardo Buscaglia Award for Empirical Research in Law and Economics (ALACDE, 2013). Os autores agradecem os comentários, discussões e sugestões de Adriana Portugal, Marcos Mendes, Karina Bugarin e Tomás Bugarin, além de dois pareceristas anônimos. Todos os erros remanescentes e opiniões expressas são da responsabilidade exclusiva dos autores. Maurício Bugarin agradece o apoio à pesquisa do $\mathrm{CNPq}$.
\end{abstract}


data econometric analysis spanning from 2002 to 2013 suggests that Ministries with higher percentages of temporary appointed managers tend to present higher levels of corruption. A mechanism design approach shows how institutions could be adjusted in order to stimulate socially-beneficial innovative management while curbing corrupt practices in the country.

\section{Keywords}

Public management. The legality constitutional principle. The efficiency constitutional principle. Innovative management. Corruption.

\section{JEL Classification}

D82. H11. H83.

\section{Introdução}

As leis e as decisões judiciais, juntamente com os instrumentos que obrigam os cidadãos a cumpri-los (polícia, judiciário, agências reguladoras, etc.), fornecem um conjunto de incentivos aos indivíduos e empresas, que têm reflexos sobre a eficiência das transações econômicas.

Há uma série de situações econômicas que não podem ser deixadas ao livre arbítrio do mercado, precisando ser reguladas e que, por isso, ficam sob a influência das leis e das instituições citadas anteriormente. Por exemplo: é preciso criar impostos para financiar atividades que são importantes para a sociedade, mas que não dão lucro e, por isso, não são oferecidas no mercado privado (defesa nacional, saneamento básico, saúde preventiva, preservação de florestas); é preciso oferecer a toda a sociedade alguns bens e serviços que, se deixados ao mercado, seriam acessíveis apenas às populações de maior renda (educação, saúde); é preciso evitar a formação de monopólios e cartéis que prejudiquem a concorrência e tornem os produtos mais caros e de menor qualidade. Tais fenômenos são conhecidos pelo termo genérico "falhas de mercado", que se refere a situações em que o livre funcionamento do mercado leva a resultados socialmente indesejáveis.

Além das falhas de mercado estudadas sob o ponto de vista econômico, a lei também tem a função de coibir outras falhas, como aquelas inerentes à conduta do ser humano. Como as normas pretendem regular a vida em sociedade, elas estabelecem comportamentos per- 
mitidos e proibidos. Ao proibir uma conduta, o Estado o faz pela ameaça de uma sanção. Por exemplo, existem leis que procuram inibir irregularidades praticadas por agentes responsáveis pela execução dos gastos públicos federais ou ainda que têm por objetivo dificultar a corrupção no setor público.

Deve-se ressaltar que o funcionamento das instituições, no qual se inclui a legislação, precisa estar corretamente calibrado de forma a contribuir com uma eficiente coordenação do sistema econômico. A definição de Douglass North, renomado autor institucionalista, deixa clara essa importância: "as instituições são as regras do jogo em uma sociedade ou, mais formalmente, são as restrições elaboradas pelos homens que dão forma à interação humana. Em consequência, elas estruturam incentivos no intercâmbio entre os homens, seja ele político, social ou econômico" (North, 1990). Portanto, essas instituições, se demasiadamente frouxas, podem gerar abusos de toda sorte; se excessivamente rígidas, podem gerar comportamento exageradamente cauteloso por parte dos indivíduos. O fato é que essas leis e instituições destinadas a corrigir falhas ou coibir comportamentos errados têm diversos graus de qualidade. Tanto podem ser eficazes na redução dos problemas, quanto podem introduzir distorções adicionais na economia e na sociedade, prejudicando a eficiência do sistema.

No ordenamento jurídico nacional, existem leis extremamente complexas e rígidas em relação ao trato com a coisa pública, como a Lei $\mathrm{n}^{\circ}$ 8.666, de 1993 (licitações e contratos administrativos) e a Lei $\mathrm{n}^{\mathrm{o}}$ 8.429, de 1992 (improbidade administrativa). Tais normas visam garantir a lisura na gestão pública; no entanto, elas impõem muitas amarras e restrições para os gestores públicos.

A própria Constituição Federal, em seu art. 37, caput, expressamente dispõe que a Administração Pública, em sua atuação, está sujeita a observar o Princípio da Legalidade em suas atividades. Isso significa que os gestores públicos, atuando em nome da Administração Pública, só podem realizar atos devidamente respaldados em prévia determinação legal. Essa realidade é diferente para a iniciativa privada, em que os particulares dispõem de ampla liberdade para sua atuação, com a única restrição de não praticarem atos vedados em lei. Em suma, enquanto o gestor da iniciativa privada pode fazer tudo aquilo que não esteja proibido pela lei, o gestor público só pode 
realizar o que estiver autorizado em lei. Por outro lado, a eficiência no uso dos recursos públicos é cada vez mais uma exigência da sociedade. Esta espera que a prestação de serviços governamentais ocorra com qualidade, utilizando racionalmente os recursos dos contribuintes. Nesse sentido, diversos estudos têm surgido a fim de discutir a qualidade das administrações públicas. ${ }^{1}$

O que se pretende neste artigo é avaliar os incentivos gerados pelas instituições no comportamento do gestor público. Mais especificamente, busca-se determinar se há incentivos a uma gestão ativa e inovadora, ou ainda a uma gestão passiva e burocrática, ou finalmente a uma gestão voltada à corrupção. Para tanto, desenvolve-se um modelo de tomada de decisão focado em dois pontos que caracterizam o gestor público. O primeiro diz respeito ao fato de ele ser ou não servidor concursado de carreira. O segundo diz respeito à sua maior ou menor preocupação pessoal com o bem-estar social gerado por sua atuação profissional. Pela análise dessas duas características, buscase prever a conduta do gestor e avaliar os incentivos que promovem comportamentos de dedicação ao serviço público ou, em oposição, comportamentos oportunistas envolvendo uso indevido de posição privilegiada no setor público.

O principal resultado obtido do modelo teórico é que regras exageradamente rígidas tendem a fazer com que o gestor de carreira adote uma postura mais cautelosa, evitando inovar e tomar decisões que possam ser futuramente questionadas e que poderiam, inclusive, implicar a perda do cargo público. Esse resultado mostra tanto um aspecto positivo como um aspecto negativo. O positivo refere-se ao menor envolvimento do gestor de carreira com atividades corruptas. $\mathrm{O}$ aspecto negativo refere-se ao menor investimento do gestor em atividades inovadoras que poderiam gerar maior benefício social. $\mathrm{O}$ modelo ainda sugere que, nesse caso de regras muito rígidas, serão basicamente os gestores com posições temporárias, não servidores de carreira, que mais se arriscarão na execução de suas atividades profissionais, tanto inovando em prol do bem-estar social, para aqueles que atribuem elevado valor a essa atividade, como em atividades ilícitas visando o benefício pessoal, para os demais.

Uma das principais hipóteses testáveis do modelo é que quanto maior for o percentual de cargos ocupados por servidores sem vín-

${ }^{1}$ Consulte, a esse respeito, Abrucio (2007). 
culo, maior tenderá a ser o questionamento judicial de sua atuação profissional. Essa hipótese é testada econometricamente usando, por um lado, dados relativos aos percentuais de cargos em direção e assessoramento superior (DAS) ocupados por servidores de carreira no Poder Executivo Federal entre 2002 e 2013 e, por outro lado, as tomadas de contas especiais (TCE) abertas e enviadas ao Tribunal de Contas da União (TCU) nesse período. Os estudos empíricos, ainda que preliminares, tendem a apoiar o resultado oriundo do modelo teórico, sugerindo que o número de TCEs relativo ao orçamento do órgão aumenta com o percentual de funcionários temporários ocupando cargos de DAS.

Diante do resultado teórico e evidência empírica preliminar encontrada, o trabalho lança mão da teoria de desenho de mecanismos para avaliar que alterações na norma legal poderiam melhor alinhar os incentivos aos gestores públicos com os objetivos do governo de dedicação, inovação em prol do bem-estar social e redução da corrupção no setor público. Essencialmente dois mecanismos são avaliados. O primeiro consiste em não punir os gestores públicos que adotarem condutas inovadoras, ainda que não previstas em lei, que contribuam para o aumento do bem-estar social. A segunda consiste em, adicionalmente, premiar esses gestores inovadores. A análise dos modelos estudados sugere que os mecanismos têm o potencial de atingir os objetivos desejados de estímulo à inovação e desestímulo à corrupção.

O presente trabalho, além desta introdução, encontra-se dividido da seguinte forma: a segunda seção faz uma rápida revisão da literatura relacionada ao objeto do estudo. A seção três expõe o desenvolvimento da modelagem econômica, focando nos incentivos dos gestores públicos ante as instituições vigentes. Na seção quatro, apresentamse dados quantitativos que retratam a realidade da administração pública federal, juntamente com testes econométricos que parcialmente reforçam o modelo teórico. A seção cinco analisa os mecanismos que podem ser adotados de forma a induzir a inovação e coibir a corrupção. Por fim, a sexta seção traz as conclusões e considerações finais do trabalho. 


\section{Breve revisão da literatura}

O presente trabalho se preocupa com dois aspectos fundamentais, mas por vezes antagônicos, da gestão pública. Por um lado, procura-se criar instituições capazes de coibir atos ilícitos associados à corrupção. Por outro lado, procura-se estimular a qualidade e a eficiência do gasto público.

No que diz respeito ao primeiro aspecto, várias pesquisas caminham no sentido de tentar entender e mensurar os prejuízos sociais resultantes da corrupção. Mauro (1995) analisa como o crescimento econômico é afetado pela corrupção em painel de dados envolvendo 67 países. Os principais resultados são os seguintes: há uma redução dos incentivos ao investimento, a sociedade sente-se menos disposta a contribuir com fundos de auxílio (doações), há perdas na arrecadação tributária, as licitações públicas geram vencedores que fornecem bens de qualidade inferior e a despesa pública fica enviesada para grandes obras em detrimento de gastos sociais, como em saúde e educação. Analogamente, Habib e Zurawicki (2002) analisam painel envolvendo 89 países, e conclui que a corrupção também reduz o investimento estrangeiro direto. ${ }^{2}$

Tanzi (1998) também defende que a eficiência do setor público fica prejudicada pela corrupção, uma vez que, por meio de fraudes em licitações, a empresa vencedora pode não ser a melhor, reduzindo o retorno do gasto e a produtividade do investimento público. Além disso, a efetividade do gasto do governo também é reduzida, pois parcelas do orçamento governamental são desviadas para o enriquecimento individual.

No caso brasileiro, em estudo comparativo entre o setor público e privado, Cândido Jr. (2001) conclui que a produtividade do gasto público é $60 \%$ da produtividade do gasto efetuado pelo setor privado. Ainda em termos de Brasil, cabe citar o ranking elaborado pela Transparência Internacional, ${ }^{3}$ organização não-governamental. Cada país recebe uma nota de zero a dez. A pontuação mais próxima de

2 Existe ainda uma vertente da literatura que estima a corrupção ser um "mal menor": "In terms of economic growth, the only thing worse than a society with a rigid, over-centralized, dishonest bureaucracy is one with a rigid, over-centralized, honest bureaucracy" (Huntington, 1968). Naturalmente, os autores do presente trabalho não comungam dessa opinião. Para maiores detalhes sobre esse debate, veja Bardhan (1997), ou ainda a discussão em Vieira, Bugarin \& Garcia (2004).

3 http://www.transparency.org/ 
zero indica que uma nação é vista como muito corrupta, enquanto as que se aproximam de dez são classificadas como menos corruptas. Para distribuir as notas, a Transparência Internacional realiza pesquisas com especialistas e executivos dos países avaliados. Após estabelecer as notas, a ONG elabora o ranking comparativo. Em 2013, o Brasil obteve nota 4,2, correspondendo a 0,5 ponto acima daquela verificada no relatório divulgado em 2010 , e 0,9 ponto acima da de 2006. Assim, percebe-se uma melhora no indicador, embora notas abaixo de cinco sejam consideradas pela Transparência Internacional como indício de sérios níveis de corrupção.

No que diz respeito ao outro tema importante para este estudo, existe ampla literatura internacional focada na preocupação com a eficiência no serviço público. Conhecida como Nova Gestão Pública, ou New Public Management, essa literatura origina-se com os esforços impetrados por diversos países ao longo dos anos 80 e 90 do século passado, no sentido de se construir um serviço público mais efetivo e eficiente de forma a reduzir o peso da carga tributária dos cidadãos, mas mantendo o mesmo volume e a mesma qualidade dos serviços públicos providos (Brignall e Modell, 2000). O expoente desse movimento é a Grã-Bretanha da Primeira Ministra Margaret Thatcher, mas ele também se materializou, tomando diferentes formas em diferentes países (Pollitt et al., 2007), chegando ao Brasil, sob a presidência de Fernando Henrique Cardoso, com o "Plano Diretor da Reforma do Aparelho de Estado" e a subsequente Reforma Gerencial de 1995. Segundo Bresser-Pereira (1999), "A Reforma Gerencial de 1995 está substituindo a atual administração pública burocrática misturada a práticas clientelistas ou patrimonialistas por uma administração pública gerencial, que adota os princípios da 'nova gestão pública' (new public management)".

A Nova Gestão Pública busca atingir maior eficiência aproximando a administração no setor público aos melhores padrões de gestão no setor privado (Hood, 1995). Diante disso, um natural conflito se mostra claro: como atingir a eficiência no setor público se a preocupação com a corrupção impõe tantos limites inexistentes no setor privado? De fato, o excesso de regulamentação, em alguns casos, gera situações ineficientes para a administração pública e obriga o gestor a tomar tantos cuidados, que é desestimulado na hora de procurar soluções criativas. Fernandes (1999) explica que, apesar de se propalar que a Lei de Licitações obriga a administração pública a comprar produtos de baixa qualidade, face ter estabelecido a regra geral da 
aquisição pelo menor preço, trata-se de um equívoco. No entanto, o próprio autor comenta que a maneira como os Tribunais de Contas fiscalizam as licitações e contratos acarretam falhas na interpretação das decisões e temor, pelos gestores públicos, da gravidade das penas impostas.

Mendes (2011), ao estudar a terceirização no serviço público e as regras a que a administração está submetida, comenta que "o modelo atual de licitação, que privilegia o menor preço, dá margem à participação de grupos mal intencionados, que montam empresas sem estrutura, para ganhar a licitação oferecendo preços baixos (até abaixo do custo), receber pagamentos antecipados e prestar um serviço de baixa qualidade e com alta probabilidade de interrupção durante a vigência do contrato, por falta de recursos para sustentar a atividade". A contribuição da presente pesquisa se encaixa justamente nesse debate mais amplo sobre como atingir eficiência no setor público, dadas as naturais regulamentações germanas ao setor.

Quanto ao preenchimento dos postos na administração pública, mais especificamente, Mendes (2011) desenvolveu trabalho que analisa a política de admissão e gerência de pessoal no governo federal, objetivando elevar o estímulo à produtividade, evitar a admissão excessiva de pessoal, melhorar a qualidade do pessoal selecionado para o serviço público, facilitar a alocação mais eficiente da mão de obra disponível, reduzir o custo da folha de pagamento e dar prioridade ao interesse público na ação cotidiana dos diversos órgãos. Um dos pontos destacados no texto é sobre os servidores comissionados.

Segundo Mendes (2011), é evidente que deve existir a possibilidade de livre nomeação para funções gerenciais mais elevadas, pois são essas pessoas que darão a orientação política da administração. Porém, à medida que se desce na escala de importância dos cargos e funções, a livre nomeação viabiliza vícios como o empreguismo e o aparelhamento partidário da máquina pública. Portanto, além da questão controle da corrupção versus maximização do retorno social da ação do gestor, surge também a questão de como servidores temporários reagem aos incentivos institucionais comparativamente aos servidores de carreira. ${ }^{4}$

${ }^{4}$ A esse respeito, Hoepers (2015), em trabalho que usa metodologia empírica semelhante à aqui desenvolvida, introduz uma nova dimensão ao debate, apresentando evidência de que ministérios brasileiros em que há maior proporção de ocupantes de cargos de DAS com filiação partidária, também apresentam maiores níveis de TCE proporcionalmente aos demais ministérios. 
A modelagem econômica desenvolvida na seção seguinte trabalha justamente com a diferenciação entre os incentivos dos servidores efetivos e servidores comissionados, estes últimos entendidos como aqueles que ocupam uma função de confiança, sem estar provido em um cargo público.

\section{Incentivos à dedicação e à corrupção no serviço público}

\subsection{As primitivas do modelo de decisão}

Visando a analisar teoricamente os incentivos com os quais se defrontam o gestor público em sua atuação profissional, seja ele funcionário de carreira ou não, este estudo inicia postulando a existência de duas categorias de profissionais que ocupam cargos de direção e assessoramento superior - DAS, os funcionários efetivos de carreira (categoria $\mathrm{C}$ ) e aqueles em cargos comissionados e temporários (categoria T). A principal distinção entre esses dois tipos de servidores ocupando cargos de DAS refere-se ao valor presente do fluxo futuro de salário que receberão: enquanto o funcionário de carreira recebe o salário, em valores presentes, de $w_{\mathrm{C}}$ ao longo de sua vida profissional, aquele servidor comissionado que vem do setor privado recebe um salário menor $w_{T}<w_{C}$ em valores presentes. A hipótese de que $w_{T}<w_{C}$ é justificada pelo fato de que $\mathrm{C}$ possui estabilidade no emprego, portanto, não será demitido a menos que se envolva em atividade ilegal, enquanto $T$ ocupa cargo eminentemente temporário, sendo demitido em curto período de tempo, como, por exemplo, ao término da gestão do ministro que o contratou.

O gestor, qualquer que seja sua origem, pública ou privada, deriva utilidade do consumo que pode adquirir com seu salário. No entanto, além desse componente da utilidade, o gestor público também se preocupa com o retorno social relacionado à sua atuação. Naturalmente, quanto mais se dedicar, quanto maior iniciativa tiver, maior será o benefício social que produzirá enquanto ocupar o cargo de DAS. Seguindo a Teoria da Motivação para o Serviço Público (Public Service Motivation, PSM, Perry \& Wise, 1990), postulamos que a contribuição para o bem-estar social é uma das principais motivações, além da questão salarial, naturalmente, para um cidadão perseguir a carreira pública. 
No entanto, independentemente de sua origem pública ou privada, diferentes indivíduos atribuem diferentes pesos ao valor de sua contribuição à sociedade, vis-à-vis o retorno pessoal privado que recebe por ocupar o cargo de DAS. Para simplificar a análise, supomos a existência de dois tipos de gestores, aqueles que atribuem elevado valor à sua contribuição social (tipo $\alpha_{A}$ ), simplesmente referido como "gestor social" no que se segue, e aqueles que atribuem baixo valor à sua contribuição social (tipo $\alpha_{B}$ ), simplesmente referido por "gestor privado", ambos relativamente ao valor que atribuem ao retorno pessoal privado em suas utilidades.

Supondo separabilidade e linearidade nas duas componentes acima explicitadas, podemos escrever a utilidade do gestor como $W+\alpha b_{s}$, em que $W$ é o valor presente da renda total auferida de sua atividade profissional, $b_{S}$ é o benefício social gerado por essa atividade e $\alpha=\alpha_{A}, \alpha_{B}$ é o tipo do gestor, com $\alpha_{A}>1>\alpha_{B}$. Note que a renda $W$ dependerá de vários fatores, como, por exemplo, a categoria do gestor ( $\mathrm{C}$ ou $T$ ), por meio de seu salário $w_{\mathrm{G}}, \mathrm{G}=\mathrm{C}, \mathrm{T}$. Além do salário do gestor naturalmente afetar sua renda, esta também é afetada pelas decisões que ele tomar no exercício de sua função. Neste modelo, existem essencialmente três possíveis decisões distintas, explicitadas a seguir:

Decisão $n$ : Nada a fazer que possa lhe trazer qualquer tipo de risco. Trata-se do gestor que cumpre sua função seguindo cuidadosamente todas as regulamentações existentes, independentemente do resultado social final. Esse gestor jamais tomará qualquer decisão arriscada que possa vir a ser questionada, mesmo que esse cuidado comprometa negativamente o benefício social de sua gestão. Esse gestor aceitará, por exemplo, fornecer produtos de baixa qualidade à sociedade desde que a empresa provedora contratada tenha sido selecionada via licitação devidamente organizada. Normalizamos em $b_{n}=0$ o benefício social gerado por essa decisão.

Decisão $s$ : Tomar decisões que aumentem a eficácia das políticas públicas sob sua responsabilidade, mesmo que essas decisões possam vir a ser questionadas na justiça. Nesse caso, o gestor focará sua atuação no retorno social que poderá ser gerado, usando para isso instrumentos que podem vir a ser questionados futuramente. Esse gestor cancelará licitações caso desconfie de conluio entre os participantes e não hesitará em contratar uma empresa fora do processo licitató- 
rio, por exemplo, se a relação benefício-custo o indicar. Trata-se de uma gestão, em certo aspecto temerária, em que o gestor ousa se desprender das amarras da legislação excessivamente limitante com o objetivo de obter um retorno social maior. Denotamos por $b_{s}>0$ o benefício social resultante dessa decisão. Naturalmente, o gestor arca com um custo pessoal associado ao esforço de dedicação a essa tarefa que resulta em benefício social, denotamos por $\psi$ esse custo pessoal.

Decisão $p$ : Tomar decisões que lhe tragam benefício privado direto via uso indevido da máquina pública, ainda que passíveis de questionamentos e punição futura. Trata-se de situações envolvendo diferentes tipos de corrupção e desvios que, ainda que ilegais, resultam na renda adicional $b_{p}>0$ para o gestor. Nesse caso não há benefício social de sua ação, por simplicidade. ${ }^{5}$ Neste caso também há um custo pessoal do esforço para o gestor implantar sua gestão corrupta que, por simplicidade, supomos igual ao custo do esforço de dedicação em prol do bem-estar social, $\psi$.

Supomos, por hipótese, que $b_{p}>b_{s}$, ou seja, o benefício privado da corrupção é maior que o retorno social da atividade temerária em prol da sociedade. Adicionalmente, supomos que $b_{p}, \alpha b_{s}>\psi, \alpha=\alpha_{A}, \alpha_{B}$, ou seja, há benefício líquido das ações inovadoras para o gestor, qualquer que seja sua escolha ( $s$ ou $p$ ) e seu tipo $\left(\alpha=\alpha_{A}, \alpha_{B}\right)$.

Como as decisões $s$ e $p$ envolvem desrespeito à regulamentação em vigor, ainda que com objetivos opostos, ambas trazem consigo o risco de um futuro questionamento com punição. A punição ocasiona a perda do cargo público, o que, no presente modelo, ocorre com a probabilidade $\pi \in(0,1)$. Caso o gestor seja punido, os benefícios, tanto o social como o privado, não são afetados. Note que a mesma probabilidade de punição é atribuída à situação em que o gestor corrupto age em benefício próprio e à situação em que o gestor honesto extrapola suas atribuições em benefício da sociedade. Essa característica visa modelar o principal problema de incentivos estudado neste trabalho: numa sociedade em que existe histórico de corrupção, as regras para evitar comportamento ilícito tendem a se tornar muito rígidas e terminam afetando a autonomia do gestor público em tomar decisões que melhor beneficiem a sociedade, sendo ambas as

\footnotetext{
5 Alternativamente, poderíamos supor um "maleficio" social $b^{\prime}{ }_{S}<0$ nessa situação. No entanto, o resultado da análise seria semelhante ao custo de mais uma variável no modelo. Portanto, essa variável foi suposta nula.
} 
decisões não previamente autorizadas em lei, as corruptas e aquelas socialmente benéficas, consideradas ilegais.

Portanto, as utilidades do gestor de categoria genérica $G=C$, $T$ e de tipo $\alpha=\alpha_{A}, \alpha_{B}$ como função de sua decisão são dadas pelas expressões a seguir.

Caso escolha a decisão $n$, sua utilidade será:

$$
U(n ;(G, \alpha))=w_{G}
$$

Caso escolha a decisão $s$, sua utilidade será:

$$
U(s ;(G, \alpha))=w_{G}(1-\pi)-\psi+\alpha b_{s}
$$

Caso escolha a decisão $p$, sua utilidade será:

$$
U(p ;(G, \alpha))=w_{G}(1-\pi)-\psi+b_{p}
$$

\subsection{As decisões ótimas dos gestores}

Tendo apresentado as primitivas do modelo, as utilidades e possíveis decisões dos gestores, analisam-se as decisões que os gestores tomarão, a depender de seus tipos e categorias. Para tanto, observe inicialmente que, como $\alpha_{A}>1>\alpha_{B}$, um gestor que atribui baixo valor ao bem-estar social (o gestor privado, do tipo $\alpha_{B}$ ) preferirá a decisão $p$ à decisão $s$, de forma que esse gestor nunca investirá no social. Já o gestor que atribui elevado valor ao bem-estar social (o gestor social, do tipo $\alpha_{A}$ ) comparará $\alpha_{A} b_{S} \operatorname{com} b_{p}$ e chegará à seguinte conclusão:

Caso $\alpha_{A} b_{s}>b_{p}$, então preferirá se arriscar em prol da sociedade a se arriscar em atividades corruptas visando benefício pessoal.

Caso $\alpha_{A} b_{s}<b_{p}$, então ocorrerá o resultado oposto, ou seja, ainda que seja mais preocupado com o bem-estar social, o gestor do tipo $\alpha_{A}$ percebe que os benefícios associados à corrupção são tão elevados, que preferirá se arriscar em atividades corruptas visando ao benefício pessoal a se arriscar em prol da sociedade. Espera-se que esse seja o caso em sociedades nas quais os benefícios da corrupção sejam 
muito significantes. Por considerar que o Brasil é um país cujas instituições já evoluíram suficientemente, supomos que este último caso não ocorre, ou seja, um gestor genuinamente motivado pelo retorno social de seu trabalho não encontra na corrupção atrativo suficiente.

Resta agora comparar as atividades $s$ e $p$ com a inação $n$. Iniciemos pelo gestor da categoria $G=C, T$ do tipo $\alpha_{B}$. Pelo visto acima, sua escolha será feita sobre as alternativas $n$ e $p$. Comparando as utilidades em (1) e (3) tem-se:

$$
U\left(p ;\left(G, \alpha_{B}\right)\right)>U\left(n ;\left(G, \alpha_{B}\right)\right) \Leftrightarrow b_{p}-\psi>\pi w_{G}
$$

A Equação (4) é bem clara quanto aos incentivos com os quais se defronta o gestor. Se o benefício adicional líquido da corrupção for maior que a perda esperada dessa atividade, o gestor a escolherá.

Observe que, como $b_{p}>b_{s}$ e $w_{T}<w_{C}$, é justamente o gestor temporário e privado que tem maior probabilidade de se tornar um gestor corrupto. Naturalmente, se o gestor de carreira optar por se dedicar a atividades envolvendo corrupção, assim também o fará o gestor temporário. Observe ainda o papel das instituições de controle: quanto maior for a probabilidade de ser punido, $\pi$, menor será o incentivo ao gestor se corromper. Esse resultado explica a ênfase dada pelo governo brasileiro aos órgãos de controle como a CGU e a Polícia Federal nos últimos anos.

Portanto, ou os gestores privados de ambas as categorias se tornam corruptos, ou apenas o gestor temporário se torna corrupto enquanto o gestor de carreira escolhe a inação, ou ainda ambos se tornam burocratas inativos. A partir deste ponto, analisa-se o gestor da categoria $G=C, T$, mas agora do tipo $\alpha_{A}$. Pelo visto acima, sua escolha será feita sobre as alternativas $n$ e $s$. Comparando as utilidades em (1) e (2) temos:

$$
U\left(s ;\left(G, \alpha_{B}\right)\right)>U\left(n ;\left(G, \alpha_{B}\right)\right) \Leftrightarrow \alpha_{A} b_{s}-\psi>\pi w_{G}
$$

A Equação (5) também é clara quanto aos incentivos com os quais se defronta o gestor. Se o benefício adicional líquido da ousadia em prol do bem-estar social for menor que a perda esperada dessa atividade, o gestor nada fará. 
Observe que, como $w_{T}<w_{C}$, espera-se que o gestor de carreira tenha maior incentivo à inação que o gestor temporário, uma vez que este último tem menos a perder caso seja punido. Vale aqui também notar o papel das instituições investigativas do estado. Quanto maior for a probabilidade de ser punido, menor o incentivo que o gestor terá em se arriscar para gerar melhor resultado social. Portanto, os gestores de ambas as categorias que valoram o bem-estar social podem se tornar burocratas inativos ou então apenas os gestores temporários se arriscarem em prol da sociedade.

A proposição a seguir resume a análise desenvolvida anteriormente, descrevendo o comportamento dos gestores segundo suas categorias e seus tipos, dada uma configuração específica dos parâmetros. É opinião dos autores que a configuração expressa nessa proposição corresponde ao estado de desenvolvimento atual das instituições nacionais, em que há um nível de controle, $\pi$, suficientemente elevado para ser levado em consideração pelos gestores nas suas decisões, mas que não é suficiente para coibir completamente a corrupção. Para efeito de completude, uma versão mais geral dessa proposição, que avalia todas as diferentes configurações dos incentivos, encontra-se apresentada no Apêndice deste trabalho. ${ }^{6}$

Proposição 1. Suponha que os parâmetros de preferências dos gestores ocupando cargos em DAS $\left(\alpha_{A}, \alpha_{B}\right)$ e das instituições ( $w_{C}, w_{P}, b_{S}$, $b_{P}$ e $\pi$ ) satisfazem as Condições de Regularidade e as Condições de Incentivos Intermediários abaixo.

(CR) Condições de Regularidade:

(i) $\alpha_{A}>1>\alpha_{B}$

(ii) $\alpha_{A} b_{s}>b_{p}>b_{s}$

(CII) Condições de Incentivos Intermediários:

(iii) $\pi w_{C}>\alpha_{A} b_{s}-\psi>\pi w_{T}$

(iv) $\pi w_{C}>b_{p}-\psi>\pi w_{T}$

6 Os autores agradecem a um parecerista anônimo por sugerir a apresentação detalhada no Apêndice. 
Então os gestores de carreira optarão por não tomar quaisquer decisões que acarretem riscos, não se envolvendo em atividades corruptas, mas tampouco tomando decisões inovadoras que maximizem o retorno social das politicas por eles geridas. Além disso, os gestores temporários se arriscarão mais, tanto ao tomar medidas visando a um melhor resultado social, para aqueles que valorizam o bem-estar social, quanto ao envolver-se em atividades corruptas visando ao benefício pessoal, para os demais.

Note o papel fundamental das instituições de controle no resultado acima, modeladas pelo parâmetro $\pi$ : quanto mais rígidas e eficazes essas instituições (ou seja, quanto maior o valor de $\pi$ ), menor será o incentivo para gestor público enveredar pelos caminhos da corrupção, mas também menor será o incentivo ao gestor público inovar em prol de uma gestão mais eficiente.

Uma consequência da análise acima é que gestores que ocupam temporariamente cargos de DAS tenderiam a correr mais riscos, o que sugere que deveria haver maior evidências de comportamento indevido nos ministérios nos quais há maior percentual de ocupantes de cargos de DAS não oriundos de carreira pública. Trata-se de uma clara consequência testável do modelo. Na próxima seção apresentamos uma estratégia empírica preliminar para testar estatisticamente essa hipótese.

\section{Evidências quantitativas preliminares}

O objetivo desta seção é apresentar evidência estatística preliminar da relação entre o percentual de cargos de DAS ocupados por funcionários oriundos da carreira pública e evidência de comportamento nocivo à res publica. Chamamos a atenção de que não é objetivo deste trabalho testar de forma abrangente e completa quais variáveis explicam o comportamento corrupto no setor público, objetivo esse por demais complexo e que foge ao escopo desta pesquisa.

\subsection{DAS e TCE}

$\mathrm{Na}$ área federal, os postos de decisão da estrutura administrativa são preenchidos com os cargos de Direção e Assessoramento Superior 
(DAS). Esses cargos podem ser ocupados por qualquer servidor ou pessoa externa ao serviço público. No entanto, o Decreto n ${ }^{\circ} 5.497$, de 2005 , estabelece que pelo menos $75 \%$ dos cargos em comissão DAS níveis 1, 2 e 3 e pelo menos 50\% dos cargos nível 4 deverão ser ocupados por servidores de carreira.

Os cargos DAS níveis 1, 2 e 3 são os que possuem menor poder de decisão. O nível 4 é referente à função de coordenador-geral, o nível 5 corresponde a diretores de departamento, e o nível 6 a secretários de ministério. Notem que para preenchimento dos níveis 5 e 6 , os mais altos, a norma não faz restrição quanto ao preenchimento, se por servidor de carreira ou por pessoa de fora do serviço público.

A Tabela 1 retrata o percentual dos cargos em comissão de direção e assessoramento superior que é preenchido por servidores efetivos, ou seja, que pertencem a alguma carreira no serviço público. Para cada ministério, durante o período de 2002 a 2013, esses percentuais foram calculados pelos autores com base em dados individualizados dos ocupantes de cargo de DAS no período, fornecidos pela Secretaria de Gestão Pública do Ministério do Planejamento, Orçamento e Gestão (SEGEP/MPOG). No geral, o percentual médio fica em torno de $65 \%$, mas há importante variação, tanto no tempo quanto entre ministérios, sendo que o percentual mínimo fica aquém de $15 \%$ e o máximo supera os $93 \%$. Entretanto, o mais interessante de se observar são as diferenças entre os ministérios. O Gráfico 1 ilustra a evolução de três dos ministérios que mais utilizam servidores de carreira para o preenchimento dos cargos de chefia e dois ministérios em situação oposta.

Note que os Ministérios da Fazenda, da Ciência e Tecnologia e do Desenvolvimento, Indústria e Comércio tratam de assuntos considerados mais complexos, que não gerenciam grandes obras e cuja finalidade primordial não envolve grandes transferências de recursos para a iniciativa privada acerca da execução de serviços. Talvez esse seja um dos motivos pelo qual técnicos de carreira estejam em postos de chefia e assessoramento. Por outro lado, os Ministérios do Turismo e do Esporte são os que menos contam com a participação de servidores de carreira nos postos de direção e assessoramento superior, sendo que no caso do Ministério do Esporte esse percentual tende a se reduzir ao longo dos anos, enquanto nos demais ministérios analisados a tendência parece ser de crescimento. Coincidentemente, 
tanto o Ministério do Turismo, ${ }^{7}$ quanto o de Esporte, ${ }^{8}$ apareceram nas capas dos principais periódicos nacionais por envolvimento em escândalos de má aplicação de recursos públicos. Vale ressaltar que as evidências midiáticas são anedóticas, sendo o principal ponto deste parágrafo a grande divergência que existe entre os diferentes ministérios e mesmo ao longo dos anos quanto ao percentual de participação de funcionários de carreira na ocupação de cargos de DAS. ${ }^{9}$

Tabela 1- Ocupação dos cargos em comissão por servidores de carreira

\begin{tabular}{|c|c|c|c|c|c|c|c|c|c|c|c|c|}
\hline \multirow[b]{2}{*}{ Ministérios } & \multicolumn{12}{|c|}{ Percentual dos DAS ocupados por efetivos } \\
\hline & 2002 & 2003 & 2004 & 2005 & 2006 & 2007 & 2008 & 2009 & 2010 & 2011 & 2012 & 2013 \\
\hline $\begin{array}{l}\text { Agricultura, Pecuária e } \\
\text { Abastecimento }\end{array}$ & 63,1 & 67,0 & 57,6 & 67,5 & 68,3 & 66,5 & 65,5 & 63,8 & 71,1 & 70,7 & 71,4 & 72,2 \\
\hline Cidades & & & 29,4 & 40,5 & 45,9 & 46,9 & 45,0 & 44,9 & 47,6 & 47,5 & 51,6 & 53,7 \\
\hline Ciência, Tecnologia e Inovação & 77,7 & 77,3 & 76,4 & 79,5 & 80,8 & 80,8 & 79,5 & 79,6 & 80,1 & 81,3 & 82,0 & 82,6 \\
\hline Comunicações & 28,1 & 29,4 & 32,5 & 29,4 & 31,9 & 33,1 & 35,1 & 39,3 & 49,6 & 53,2 & 58,9 & 57,7 \\
\hline Cultura & 54,6 & 48,8 & 44,7 & 44,9 & 49,5 & 49,2 & 50,3 & 48,5 & 47,4 & 47,8 & 48,7 & 49,0 \\
\hline Defesa & 44,4 & 41,3 & 42,0 & 42,0 & 43,7 & 43,7 & 42,8 & 42,8 & 42,1 & 39,5 & 40,6 & 34,9 \\
\hline Desenvolvimento Agrário & 61,9 & 63,9 & 66,5 & 66,1 & 66,5 & 68,4 & 70,3 & 70,4 & 71,7 & 70,0 & 70,8 & 73,2 \\
\hline $\begin{array}{l}\text { Desenvolvimento, Indústria e } \\
\text { Comércio Exterior }\end{array}$ & 61,9 & 63,9 & 66,5 & 66,1 & 66,5 & 68,4 & 70,3 & 70,4 & 71,7 & 70,0 & 70,8 & 73,2 \\
\hline $\begin{array}{l}\text { Desenvolvimento Social e } \\
\text { Combate à Fome }\end{array}$ & & & 38,2 & 43,3 & 44,0 & 44,7 & 44,2 & 47,4 & 42,9 & 44,6 & 45,3 & 46,9 \\
\hline Educação & 56,4 & 51,7 & 51,9 & 55,8 & 62,3 & 66,8 & 65,6 & 62,5 & 65,7 & 67,2 & 68,9 & 69,7 \\
\hline Esporte & 43,5 & 34,8 & 31,5 & 31,4 & 35,2 & 27,7 & 23,9 & 23,6 & 23,6 & 22,9 & 21,2 & 24,8 \\
\hline Fazenda & 82,9 & 82,6 & 83,2 & 84,9 & 85,5 & 88,1 & 87,8 & 88,2 & 88,2 & 88,6 & 88,3 & 88,8 \\
\hline Integração Nacional & 52,2 & 52,8 & 51,1 & 55,1 & 62,6 & 62,7 & 62,3 & 60,0 & 58,0 & 60,4 & 60,1 & 58,6 \\
\hline Justiça & 53,5 & 51,5 & 50,8 & 52,3 & 54,1 & 54,0 & 51,9 & 50,9 & 49,0 & 50,4 & 51,8 & 55,8 \\
\hline Meio Ambiente & 56,8 & 52,5 & 56,3 & 62,1 & 66,0 & 70,0 & 75,0 & 76,9 & 80,6 & 81,4 & 82,6 & 83,5 \\
\hline Minas e Energia & 50,0 & 40,2 & 40,5 & 41,8 & 46,7 & 47,0 & 46,4 & 46,6 & 44,0 & 46,2 & 45,4 & 45,0 \\
\hline Pesca e Aquicultura & & & & & & & & & & 22,0 & 15,7 & 13,5 \\
\hline $\begin{array}{l}\text { Planejamento, Orçamento e } \\
\text { Gestão }\end{array}$ & 67,2 & 66,5 & 64,4 & 64,0 & 65,6 & 66,5 & 66,1 & 66,0 & 66,4 & 66,4 & 66,4 & 66,9 \\
\hline Previdência Social & 91,1 & 90,6 & 90,2 & 93,6 & 92,9 & 89,4 & 89,7 & 90,0 & 88,2 & 88,1 & 88,1 & 89,5 \\
\hline Relações Exteriores & 95,5 & 95,3 & 94,8 & 93,6 & 93,2 & 93,2 & 92,8 & 92,2 & 91,6 & 91,9 & 92,7 & 91,7 \\
\hline Saúde & 74,6 & 68,0 & 68,3 & 69,0 & 70,6 & 69,6 & 68,2 & 66,4 & 67,8 & 72,1 & 73,1 & 73,1 \\
\hline Trabalho e Emprego & 60,3 & 55,6 & 54,6 & 58,1 & 62,5 & 60,7 & 63,3 & 63,8 & 65,4 & 67,9 & 70,0 & 66,7 \\
\hline Transportes & 48,7 & 42,9 & 49,1 & 53,0 & 54,6 & 51,2 & 49,5 & 50,5 & 54,7 & 62,1 & 66,6 & 70,1 \\
\hline Turismo & & 18,5 & 20,9 & 23,2 & 22,8 & 24,2 & 24,6 & 24,5 & 25,3 & 28,4 & 33,0 & 35,5 \\
\hline
\end{tabular}

Fonte: Elaboração dos autores a partir de dados cedidos por Felix Lopez, Maurício Bugarin e Karina Bugarin.

7 Estadão, 12/08/2011.

8 Folha de São Paulo, de 05/11/2011.

9 Para uma discussão mais aprofundada sobre a ocupação dos cargos de DAS no Brasil vide, por exemplo, Lopez, Bugarin e Bugarin, 2014. 


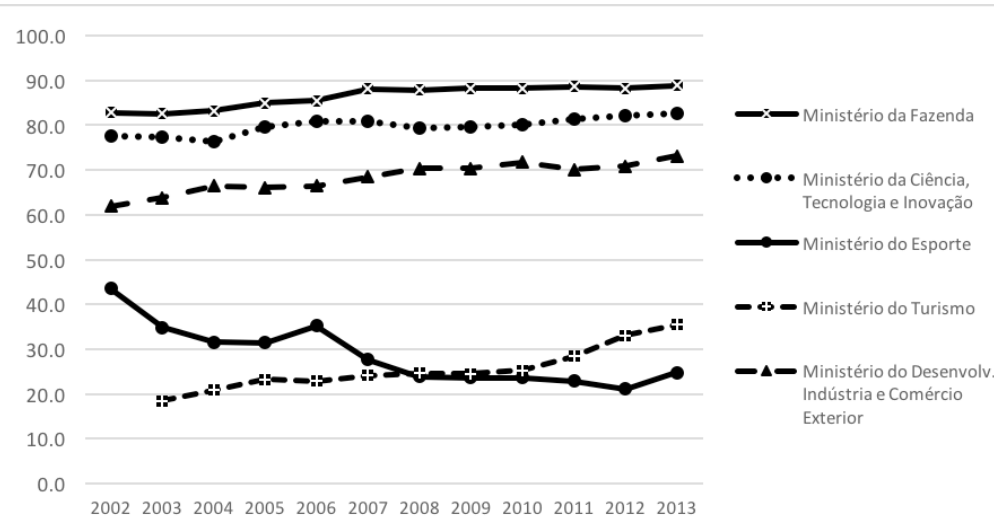

Gráfico 1 - Evolução do preenchimento dos cargos em comissão por servidor de carreira

Fonte: Elaboração dos autores a partir de dados cedidos por Felix Lopez, Maurício Bugarin e Karina Bugarin.

Essas evidências poderiam sugerir um comportamento mais oportunista de pessoas que não possuem vínculo permanente com o serviço público. Uma maneira de tentar testar empiricamente essa sugestão é analisar se existe alguma relação entre a prática de delitos na administração pública e a existência de mais ou menos servidores comissionados na estrutura de poder dos ministérios.

A variável que será utilizada para quantificar os problemas detectados é o número de Tomadas de Contas Especiais (TCE) ${ }^{10}$ abertas e enviadas para o Tribunal de Contas da União (TCU). Segundo o art. 63 da Portaria Interministerial MPOG/MF/CGU n. ${ }^{\circ}$ 127/2008, "Tomada de Contas Especial é um processo devidamente formalizado, dotado de rito próprio, que objetiva apurar os fatos, identificar os responsáveis e quantificar o dano causado ao Erário, visando ao seu imediato ressarcimento".

É importante esclarecer que, antes da abertura da Tomada de Contas Especial, conforme o constante do art. $3^{\circ}$ da Instrução Normativa n. ${ }^{\circ}$ 56/2007 do TCU, a autoridade competente do órgão ou entidade deve esgotar todas as medidas administrativas internas objetivando

${ }^{10}$ Essa variável também é usada em Hoepers (2015) para testar relação entre o percentual de funcionários filiados a partidos ocupando cargo de DAS em um ministério e evidência de corrupção nesse ministério. 
a obtenção do ressarcimento pretendido. Portanto, a instauração de uma TCE é uma medida extrema em que há forte indício de desvio de recurso público. A Controladoria-Geral da União (CGU) disponibiliza dados anuais do número de processos analisados pela CGU com contas consideradas irregulares e, portanto, encaminhados ao (TCU) para julgamento.

Buscamos testar econometricamente o grau de associação linear entre o número de TCEs e o percentual de cargos em comissão que são preenchidos com servidores de carreira. No entanto, é natural supor que, quanto maior for o orçamento de um ministério, tanto maiores serão as oportunidades de uso indevido desse orçamento e, possivelmente, tanto maior será o número de TCEs. Visando controlar esse viés de tamanho, utilizamos em nossos estudos econométricos a variável dependente TCEA que é o número de TCEs dividido pela despesa executada de cada ministério (em bilhões de reais) no ano respectivo, em valores constantes do ano 2012, deflacionada pelo IPCA.

Tabela 2 - Quantidade de Tomadas de Contas Especiais (TCE) instauradas por despesa executada (despesa executada em bilhões de reais em valores constantes de 2012)

\begin{tabular}{|c|c|c|c|c|c|c|c|c|c|c|c|c|}
\hline \multirow[t]{2}{*}{ Ministérios } & \multicolumn{12}{|c|}{$\begin{array}{c}\text { Número de TCE enviadas ao TCU por despesa executada anual de cada } \\
\text { órgãoQuantidade/R\$ bilhões de } 2012\end{array}$} \\
\hline & 2002 & 2003 & 2004 & 2005 & 2006 & 2007 & 2008 & 2009 & 2010 & 2011 & 2012 & 2013 \\
\hline $\begin{array}{l}\text { Agricultura, Pecuária e } \\
\text { Abastecimento }\end{array}$ & 8,63 & 3,98 & 3,54 & 2,37 & 1,16 & 2,16 & 1,96 & 1,82 & 2,16 & 1,22 & 3,47 & 1,18 \\
\hline Cidades & & 0,00 & 4,98 & 0,00 & 1,66 & 2,56 & 1,96 & 2,00 & 7,65 & 3,01 & 3,90 & 3,49 \\
\hline Ciência, Tecnologia e Inovação & 7,39 & 6,54 & 17,77 & 7,67 & 3,72 & 4,84 & 12,01 & 7,56 & 17,11 & 1,31 & 1,33 & 6,18 \\
\hline Comunicações & 40,75 & 9,15 & 23,88 & 12,41 & 13,52 & 11,10 & 9,90 & 14,89 & 24,73 & 10,95 & 6,71 & 9,30 \\
\hline Cultura & 91,51 & 91,07 & 62,08 & 49,95 & 68,21 & 66,67 & 78,96 & 47,92 & 10,03 & 40,83 & 36,41 & 91,91 \\
\hline Desenvolvimento Agrário & 3,10 & 1,70 & 3,44 & 1,19 & 1,97 & 3,66 & 2,78 & 13,20 & 11,19 & 6,91 & 20,17 & 27,33 \\
\hline $\begin{array}{l}\text { Desenvolvimento, Indústria e } \\
\text { Comércio Exterior }\end{array}$ & 15,38 & 4,18 & 6,70 & 2,71 & 3,37 & 2,23 & 3,40 & 1,54 & 1,45 & 0,73 & 1,92 & 6,77 \\
\hline $\begin{array}{l}\text { Desenvolvimento Social e } \\
\text { Combate à Fome }\end{array}$ & & 0,00 & 8,64 & 1,54 & 3,36 & 6,81 & 8,53 & 4,32 & 1,25 & 0,64 & 1,14 & 2,17 \\
\hline Educação & 3,61 & 22,93 & 11,24 & 22,36 & 8,10 & 7,51 & 3,79 & 2,39 & 2,75 & 0,77 & 1,16 & 3,66 \\
\hline Esporte & 95,86 & 123,3 & 44,39 & 67,21 & 4,27 & 3,63 & 22,94 & 66,28 & 59,60 & 72,50 & 33,59 & 84,20 \\
\hline Fazenda & 0,06 & 0,08 & 0,11 & 0,04 & 0,04 & 0,04 & 0,01 & 0,02 & 0,05 & 0,00 & 0,04 & 0,02 \\
\hline Integração Nacional & 6,73 & 6,14 & 10,14 & 14,31 & 9,36 & 11,63 & 7,75 & 5,45 & 6,27 & 8,85 & 11,88 & 10,67 \\
\hline Justiça & 1,12 & 1,03 & 2,24 & 1,88 & 3,67 & 7,97 & 0,62 & 0,40 & 0,47 & 0,81 & 2,04 & 1,19 \\
\hline Meio Ambiente & 24,80 & 37,81 & 62,81 & 34,97 & 31,77 & 37,63 & 14,11 & 14,81 & 18,97 & 8,17 & 712,84 & 411,86 \\
\hline Minas e Energia & 0,15 & 0,00 & 0,00 & 0,06 & 0,00 & 0,00 & 0,00 & 0,12 & 0,00 & 0,00 & 0,04 & 0,04 \\
\hline Pesca e Aquicultura & & & & & & & & 0,00 & 0,00 & 8,66 & 71,46 & 99,83 \\
\hline
\end{tabular}


Tabela 2 - Quantidade de Tomadas de Contas Especiais (TCE) instauradas por despesa executada (despesa executada em bilhões de reais em valores constantes de 2012) (Continuação)

\begin{tabular}{|c|c|c|c|c|c|c|c|c|c|c|c|c|}
\hline \multirow[t]{2}{*}{ Ministérios } & \multicolumn{12}{|c|}{$\begin{array}{c}\text { Número de TCE enviadas ao TCU por despesa executada anual de cada } \\
\text { órgãoQuantidade/R\$ bilhões de } 2012\end{array}$} \\
\hline & 2002 & 2003 & 2004 & 2005 & 2006 & 2007 & 2008 & 2009 & 2010 & 2011 & 2012 & 2013 \\
\hline $\begin{array}{l}\text { Planejamento, Orçamento e } \\
\text { Gestão }\end{array}$ & 3,26 & 4,83 & 1,25 & 103,2 & 68,04 & 29,93 & 8,74 & 4,92 & 7,30 & 7,34 & 3,70 & 0,41 \\
\hline Previdência Social & 0,25 & 0,25 & 0,00 & 0,00 & 0,01 & 0,00 & 0,02 & 0,00 & 0,00 & 0,02 & 0,15 & 0,30 \\
\hline Saúde & 6,33 & 5,56 & 6,80 & 4,50 & 3,76 & 7,85 & 5,61 & 7,91 & 4,39 & 3,96 & 5,81 & 7,58 \\
\hline Trabalho e Emprego & 0,07 & 0,14 & 0,10 & 0,12 & 0,93 & 0,63 & 0,42 & 3,09 & 0,95 & 0,45 & 1,83 & 2,25 \\
\hline Transportes & 1,90 & 2,73 & 1,71 & 1,54 & 0,52 & 0,10 & 0,37 & 0,25 & 0,26 & 0,28 & 0,62 & 1,17 \\
\hline Turismo & & 0,00 & 0,00 & 0,00 & 7,09 & 6,91 & 25,27 & 20,52 & 32,73 & 64,89 & 204,4 & 422,2 \\
\hline
\end{tabular}

Fonte: Controladoria-Geral da União e Orçamento da União, dados do orçamento gentilmente cedidos por Felix Lopez.

A Tabela 2 apresenta os valores da variável TCEA. Note que foram excluídos dessa tabela o Ministério da Defesa e o Ministério das Relações Internacionais; isso ocorreu pelo fato de esses dois ministérios possuírem sistemas internos de auditorias que não passam pela coordenação da CGU. ${ }^{11}$

\subsection{Variável independente e variáveis dependentes}

A variável dependente da fórmula funcional que será regredida é:

TCEA $_{i t}$ : Número de TCEs abertas e enviadas para o Tribunal de Contas da União (TCU) referentes às contas do ministério $i$ ano $t$, dividido pelo orçamento executado do ministério nesse ano, em bilhões de reais, em valores constantes de 2012, deflacionados pelo IPCA. Os dados referentes às TCEs foram obtidos da Controladoria Geral da União (CGU), enquanto os dados referentes à despesa executada foram calculados por Felix Lopez (IPEA) a partir de dados obtidos da Secretaria do Tesouro Nacional (STN).

11 Vide, a esse respeito, a Instrução Normativa N. 01 de 6/4/2001 da Secretaria Federal de Controle Interno. 
A variável endógena é influenciada pelas seguintes variáveis independentes:

\section{Percentual de DAS de carreira:}

CARREIRA $_{i t}$ : Percentual dos cargos de DAS ocupados por funcionários de carreira no ministério $i$ no ano $t$. Os dados referentes a essa variável foram calculados com base em dados obtidos da Secretaria de Gestão Pública do Ministério do Planejamento. De acordo com as discussões anteriores, espera-se que o coeficiente desta variável tenha sinal negativo.

\section{Dummies de ano: ${ }^{12}$}

D03: Dummy assumindo valor 1 no ano 2003 e zero nos demais. Não está claro, ex-ante, que sinal deve ter o coeficiente desta variável. Analogamente definem-se as variáveis D04, D05,.., Dl3 para os anos 2004, 2005,...,2013, respectivamente.

\section{Controles ministeriais:}

DESPESA $_{i t}$ : Trata-se da despesa executada no ministério $i$ no ano $t$, em valores constantes de 2012, em bilhões de reais. O objetivo desta variável é controlar pelo tamanho do gasto do ministério. Como a variável dependente já se encontra dividida pela despesa, não há clara expectativa sobre o efeito desta variável.

$\mathrm{DAS}_{i t}$ : Número de posições de DAS no ministério $i$ no ano $t$. Como os principais articuladores das políticas públicas são os diretores dos ministérios, espera-se que um maior número de cargos de DAS esteja associado a maiores oportunidades de desvios, aumentando o número de TCEA's.

$\mathrm{SERV}_{i t}$ : Número total de servidores no ministério $i$ no ano $t$, em 10 mil unidades. Esta variável vis testar novamente o efeito do tamanho do ministério, agora em termos de empregados, sobre a variável dependente. Não há clara expectativa quanto ao efeito dessa variável.

\footnotetext{
12 Os autores agradecem a um parecerista anônimo pela sugestão da inclusão das dummies de ano.
} 


\section{Tipos dos ministérios:}

NOVOS $_{i}$ : Dummy que assume valor 1 se o ministério $i$ tiver sido criado dentro do período da amostra, ou seja, entre 2002 e 2013. Existem três categorias de ministérios no período abarcado pelo estudo econométrico, de 2002 a 2013, segundo a fundação do ministério. Os mais antigos foram fundados anteriormente a 2002. A segunda categoria consiste dos ministérios fundados em 2003 (MCID, MDSCF e MTUR). Finalmente, a terceira categoria consiste do MPA, ministério fundado em 2009. Não está claro qual sinal deverá ter o coeficiente desta variável.

CONTROLE $_{i}$ : Existe, na literatura de federalismo fiscal, uma distinção entre ministérios que têm por finalidade básica a aplicação de recursos públicos, comumente chamados de "gastadores" e aqueles que têm como finalidade básica a arrecadação e o controle dos gastos, chamados comumente de "controladores. ${ }^{13 "}$ Esses últimos são, no caso do Brasil, o Ministério do Planejamento, Orçamento e Gestão e o Ministério da Fazenda. A variável CONTROLE é uma dummy que assume valor 1 para esses ministérios e zero para os demais. Considerando a maior preocupação dos ministérios de controle com o gasto público, espera-se que o coeficiente desta variável tenha sinal negativo.

SOCIAL $_{i}$ : Dummy que associa valor 1 aos ministérios responsáveis pela condução das políticas sociais do governo. São eles os Ministérios da Educação, da Saúde, do Esporte e do Desenvolvimento Social e Combate à Fome. Não está claro o sinal dessa variável.

INFRAESTRUTURA $A_{i}$ : Dummy que assume valor 1 nos Ministérios responsáveis pelas políticas públicas de infraestrutura. São eles o Ministério das Minas e Energia, da Integração Nacional e dos Transportes. Por ser um setor que envolve vultosos gostos do governo, espera-se um sinal positivo para essa variável.

13 Veja, a esse respeito, por exemplo, Von Hagen (2002). 


\section{Controles políticos}

IDEOLOGIA $_{i t}$ : O objetivo desta variável é determinar se a ideologia do partido no poder em um ministério afeta a TCEA. Para tanto, partiu-se de uma variável numérica tomando valor de 0 a 10 de acordo com a ideologia do partido do ministro segundo a classificação em Zucco Jr. (2014). ${ }^{14}$ Nessa classificação, valores mais baixos correspondem a ideologias mais à esquerda o espectro político nacional, enquanto valores mais elevados correspondem a ideologias mais à direita. A Tabela Al no Apêndice, disponível em Lopez, Bugarin e Bugarin (2015), apresenta os valores da ideologia usados neste traba1ho. Foi usada interpolação linear simples para anos não explicitados nessa classificação, usando para tanto os dois anos mais próximos, sendo usados pesos para refletir a proximidade dos anos extremos do intervalo considerado com o ano em questão. Nos casos em que o ministro no cargo não possuía filiação partidária, classificou-se sua ideologia como aquela atribuída ao presidente. Essa escolha reflete o fato de que a seleção de um ministro sem partido indica que o/a presidente não negociou com partidos para sua tomada de decisão. No ano em que houve mudança partidária, tomou-se a ideologia do ministro entrante.

MUDANÇA MINISTERIAL $\mathrm{L}_{i t}$ : Dummy tomando valor 1 quando tiver havido mudança de ministro no ministério $i$ no ano $t$. Estima-se que a mudança ministerial aumente o número de TCE's no ministério correspondente.

ROTATIVIDADE DE DAS $_{i t}$ : Valor entre 0 e 1 que mede a taxa de rotatividade de ocupantes de cargos de DAS no ministério $i$ no ano $t .{ }^{15}$ Espera-se que quanto maior for a rotatividade em um ministério, maior seja a quantidade de TCE's.

PRIMEIRO ANO DE MANDATO M D $_{t}$ mmy tomando valor 1 se o ano $t$ corresponder ao primeiro ano de mandato presidencial. Esperase que no último ano de um mandato presidencial a preocupação com a reeleição, própria ou de seu partido, fará com que o presidente se exponha mais, aumentando o número de TCE's no ano seguinte.

14 Veja também, a esse respeito, Zucco Jr. (2011)

15 Dados gentilmente cedidos por Felix Lopez, Maurício Bugarin e Karina Bugarin, vide Lopez, Bugarin e Bugarin (2014). 
Tabela 3 - Sinais esperados dos coeficientes das variáveis independentes

\begin{tabular}{l|c}
\hline Variável independente & Sinal esperado \\
\hline CARREIRA & - \\
D03 a D13 & $?$ \\
DESPESA & $?$ \\
DAS & + \\
SERVIDORES & $?$ \\
NOVOS & $?$ \\
CONTROLE & - \\
SOCIAL & $?$ \\
INFRAESTRUTURA & + \\
IDEOLOGIA & + \\
MUDANÇA MINISTERIAL & + \\
ROTATIVIDADE DAS & + \\
\hline
\end{tabular}

Fonte: Elaboração própria.

A Tabela 3 a seguir sumariza os sinais esperados dos coeficientes das variáveis independentes, enquanto a Tabela 4 apresenta as estatísticas básicas das variáveis que não são dummies.

Tabela 4 - Estatísticas Básicas das Variáveis dos Estudos Econométricos Número de observações: 250

\begin{tabular}{l|cccc}
\hline Variável & Média & Desvio padrão & Mínimo & Máximo \\
\hline TCEA & 15,16 & 36,25 & 0 & 422,15 \\
CARREIRA & $58,12 \%$ & $17,87 \%$ & $13,5 \%$ & $93,6 \%$ \\
DESPESA & 71,88 & 210,82 & 0,10 & 1087,75 \\
DAS & 832,42 & 595,64 & 161 & 2773 \\
SERVIDORES (10 mil) & 2,28 & 4,57 & 0,209 & 24,7961 \\
VARIAÇÃO IDEOLÓGICA & 3,60 & 1,08 & 2,06 & 6,93 \\
ROTATIVIDADE DAS & 28,62 & 11,07 & 10,24 & 71,72 \\
\hline
\end{tabular}

Fonte: Cálculos dos autores e dados cedidos por Felix Lopes, Maurício Bugarin e Karina Bugarin.

\subsection{Os modelos e os métodos econométricos explorados}

A estratégia econométrica consistiu em iniciar com um modelo mais reduzido, incorporando poucas variáveis para depois incorporar sucessivamente mais variáveis explicativas. Ao todo foram estimados 3 modelos, conforme descrito a seguir. 
Todos os modelos estimaram uma constante. O Modelo 1 incorporou a variável CARREIRA e as variáveis dummies referentes aos anos (D03 a D13), sendo o ano de 2002 tomado como referência de comparação. O Modelo 2 incorporou, ademais, as variáveis de Controles dos ministérios GASTO EXECUTADO, DAS, SERVIDORES, MINISTÉRIOS NOVOS, CONTROLE, SOCIAL e INFRAESTRUTURA. Finalmente, o Modelo 3 incorporou ao modelo anterior as variáveis Políticas IDEOLOGIA, MUDANÇA MINISTERIAL e ROTATIVIDADE DE DAS.

Para se determinar se a regressão no formato POLS adequa-se aos dados presentes foram aplicados, dois testes para cada um dos modelos. O primeiro, o teste $\mathrm{F}$ de Chow foi usado para se testar se uma regressão em formato de painel com efeitos fixos seria ou não mais adequada que o mais simples Método do Mínimos Quadrados Empilhados (POLS). Os resultados, apresentados no Apêndice Al, indicam que sob as três especificações o método de efeitos fixos é mais adequado que POLS. Para todos os testes o $p$-valor ficou abaixo de 0,0001. Em seguida foi aplicado o Teste do Multiplicador Lagrangeano de Breusch-Pagan para se determinar se uma regressão em formato de painel com efeitos aleatórios seria ou não mais adequada que o mais simples Método do Mínimos Quadrados Empilhados (POLS). Todos os testes, disponíveis no Apêndice A2, indicaram fortemente a superioridade da regressão em painéis. Para todos os testes o $p$-valor também ficou abaixo de 0,0001 .

Feita, então, a escolha pelo uso de dados em painéis, a decisão seguinte disse respeito ao uso de efeitos fixos ou aleatórios. O teste de Hausman aplicado a cada um dos modelos indicou a clara opção pela regressão com efeitos aleatórios (a 1\% de significância), conforme detalhado no Apêndice A3. O menor $p$-valor encontrado foi 0,4741 . Ao se fazer a opção pelo uso de efeitos aleatórios, aplicou-se então o Teste do Quociente de Verossimilhança (Likelihood ratio test, LRTest) para se avaliar a presença de heterocedasticidade nos dados. As estatísticas encontradas indicaram presença de heterocedasticidade para todos os modelos, conforme descrito no Apêndice A4. Para todos os testes o $p$-valor ficou abaixo de 0,0001. Finalmente, aplicou-se o Teste de Wooldridge para a presença de autocorrelação dos resíduos. O teste indica rejeição da hipótese nula de ausência de autocorrelação de primeira ordem nos modelos a 5\% de significância, conforme detalhado no Apêndice A5. O menor $p$-valor encontrado 
foi 0,0682. Diante da evidência de heterocedasticidade e de autocorreção, optamos pelo uso dos regressores de Prais-Winsten com correção tanto para heterocedasticidade como para autocorrelação. ${ }^{16}$

Os resultados detalhados dos três modelos encontram-se apresentados na Tabela A6 no Apêndice. Considerando que os três modelos reforçam os mesmos efeitos (vide Apêndice), apresentamos na Tabela 5 uma versão reduzida de uma regressão incluindo apenas as variáveis que se mostraram significantes. Os resultados na Tabela 5 (bem como nas regressões apresentadas no Apêndice) mostram o efeito sugerido pelo modelo teórico. Quando maior for a proporção de funcionários de carreira ocupando cargos de DAS, menor será a ocorrência de TCE por unidade de orçamento autorizado (em bilhões de reais, a valores constantes de 2012). De acordo com os coeficientes encontrados, uma redução de 10 pontos na participação relativa de funcionários de carreira na ocupação dos cargos de DAS em um ministério (de $70 \%$ para $60 \%$, por exemplo) tende a gerar quase 7 TCE's por bilhão de despesa desse ministério. Vale notar que o resultado somente é significante ao nível de $5 \%$.

Tabela 5 - Painéis com efeitos aleatórios e erros-padrão de Prais-Winsten Variável dependente - Número de TCE's por bilhão de gasto executado (modelo reduzido)

\begin{tabular}{|c|c|c|c|c|c|}
\hline Variáveis explicativas & Coeficiente & & Erro-padrão & Estatística $z$ & $p$-Valor \\
\hline Carreira & $-67,59$ & ** & 32,86 & $-2,02$ & 0,040 \\
\hline D13 & 19,88 & $* * *$ & 5,55 & 3,58 & 0,000 \\
\hline DAS & $-0,008$ & ** & 0,004 & $-1,97$ & 0,049 \\
\hline Infraestrutura & $-23,70$ & *** & 8,10 & $-2,92$ & 0,003 \\
\hline Constante & 64,37 & $* * *$ & 23,22 & 2,77 & 0,006 \\
\hline \multicolumn{6}{|l|}{ Observações incluídas } \\
\hline Número de grupos & \multicolumn{3}{|l|}{22} & & \\
\hline $\mathrm{R}^{2}$ & \multicolumn{3}{|l|}{12,10} & & \\
\hline \multicolumn{6}{|c|}{ ***: Estatisticamente significante ao nível de significância de $1 \%$} \\
\hline \multicolumn{6}{|c|}{ **: Estatisticamente significante ao nível de significância de 5\% } \\
\hline \multicolumn{6}{|c|}{ *: Estatisticamente significante ao nível de significância de $10 \%$} \\
\hline
\end{tabular}

Ademais, não se nota uma tendência temporal clara, sendo o ano de 2013 o único que mostrou efeito significante. Nesse caso, nota-se um importante aumento de quase 20 TCE por bilhão de real executado, na média.

${ }^{16}$ Vide Prais \& Winsten (1954), implementado em Stata pelo comando xtpcse, het c(arl). 
O coeficiente da variável DAS, significante a $5 \%$, contradiz a expectativa inicial, sugerindo que o aumento no quadro de DAS pode reduzir o número de TCE's. De fato, a cada 10 novos postos de DAS em um ministério há, em média, uma redução de quase 0,1 TCE por bilhão de gasto autorizado. Esse resultado sugere que o aumento no número de posições de DAS, em torno de $38 \%$ de crescimento de 1999 a 2013 de acordo com Felix et al. (2014), pode ser benéfico para a administração pública. O resultado também sugere que parte dos processos de TCE podem ser motivados por incompetência administrativa e não por desonestidade, situação essa que seria minimizada à medida que aumentasse a supervisão com o número de cargos de DAS em um ministério. Esta hipótese é deixada aqui e na conclusão como sugestão para pesquisa futura.

Os resultados também sugerem, com um nível de segurança de $1 \%$, que os ministérios responsáveis pela implantação da política nacional de infraestrutura apresentam menores volumes de TCE's. Mais especificamente, configura-se uma redução de quase 24 TCE's por bilhão de gasto nesses ministérios em comparação com a média dos demais. Trata-se de resultado inesperado, uma vez que são justamente esses os ministérios responsáveis por grandes e dispendiosas obras. Um aprofundamento desse resultado também é deixado aqui como sugestão para pesquisas futuras.

Apesar de nossos testes sugerirem o uso do da regressão em painéis com efeitos aleatórios, convém apresentar aqui uma discussão sobre os resultados obtidos aplicando-se os métodos de mínimos quadrados empilhados e de painéis com efeitos fixos, usando para tanto os desvios-padrão corrigidos por Driscoll \& Kraay (1998). Os detalhes das respectivas regressões encontram-se no Apêndice deste.

O método POLS gera essencialmente os mesmos resultados que o método de painéis com efeitos aleatórios, sendo a única diferença importante a não significância da variável DAS, cujo efeito em termos reais já era bastante reduzido no modelo original. Por outro lado, o método de painéis com efeitos fixos revela o desconcertante resultado de não significância da variável chave deste estudo, o percentual de funcionários de carreira ocupando cargo de DAS (CARREIRA). Ademais, o sinal é invertido e se torna positivo. Este último resultado sugere certa fragilidade da abordagem econométrica deste trabalho, que deve ser vista com reserva. Com certeza, estudos mais 
aprofundados são necessários para melhor se entender a o comportamento dos funcionários públicos em cargos de direção, sejam eles de carreira ou comissionados.

Uma possível explicação para essa fragilidade encontra-se no fato de que o incentivo ao comportamento ilícito depende, conforme explicitado na análise teórica, não somente da origem do funcionário (carreira \& comissionado), mas também de seu tipo (social \& pessoal). Naturalmente, a Teoria da Motivação pelo Serviço Público (Perry \& Wise, 1990) sugere que exista maior proporção de servidores do tipo social dentre os funcionários de carreira, uma vez que a teoria prevê que "muitos indivíduos predispostos às normas e emoções públicas atuam no interesse público, mesmo quando fazendo isso vai de encontro ao seu interesse pessoal" (Brewer \& Selden, 1998). No entanto, como o tipo de um agente é sua informação privada, a caracterização por meio da origem da carreira pode ser inadequada. ${ }^{17}$

Outra possível explicação se encontra nas limitações do poder explicativo dos modelos analisados, sendo que o modelo com efeitos fixos é aquele que possui o menor valor para o $R^{2}$, sendo este inferior a $6 \%$. Portanto, um estudo econométrico mais aprofundado faz-se necessário para que seja possível reforçar ou negar o papel do percentual de funcionários de carreira em cargos de DAS sobre a incidência de corrupção no serviço público federal ${ }^{18}$.

\section{Alinhando os incentivos: uma abordagem de desenho de meca- nismos}

O resultado encontrado nos modelos teórico e empírico é desanimador, pois sugere que a estrutura legal vigente tende a inibir a ação dos funcionários públicos de carreira em prol da sociedade, estimulando -os a adotarem uma postura burocrática de baixo retorno social. Em termos da discussão sobre a Nova Gestão Pública, o resultado sugere que nossas instituições não contribuem para uma maior eficiência do setor público.

17 Agradecemos a um parecerista anônimo por chamar a atenção para este fato.

18 Uma tentativa foi feita no sentido de se incluir a possibilidade do comportamento irregular somente gerar uma TCE com certa defasagem no tempo, conforme sugestão de um parecerista anônimo. No entanto, essa tentativa não gerou melhores resultados. 
O equilíbrio institucional vigente indica as seguintes questões. Deverá a sociedade aceitar esse resultado ineficiente? Há possibilidades de alteração do arcabouço legal do país de forma a alterar os incentivos de forma que os gestores sociais realmente dediquem seus esforços ao bem-estar social e os gestores privados não se dediquem a atividades danosas à sociedade? A presente seção lança mão da teoria de desenho de mecanismos para responder a essas questões.

\subsection{Protegendo o gestor inovador}

Uma forma natural de se estimular o gestor de carreira que valora o bem-estar social a inovar é simplesmente não puni-lo, caso seja confirmado o benefício social de sua ação. A nova instituição funcionaria da seguinte forma. Assim como ocorre atualmente, os gestores continuam sendo investigados pelos órgãos de controle, de forma que há uma probabilidade $\pi$ de ser identificada ação irregular do gestor. No entanto, caso os órgãos de controle confirmem que a ação inovadora foi benéfica à sociedade, o gestor não perderá seu emprego. Portanto, a utilidade do gestor que inova em prol da sociedade passa a ser $U\left(s ;\left(G, \alpha_{A}\right)\right)=w_{G}-\psi+\alpha_{A} b_{s}$. Lembrando que $U(n ;(G, \alpha))=w_{G}$ e ainda que, naturalmente, o benefício $\alpha_{A} b_{S}$ supera o custo do esforço $\psi$, concluímos que o gestor de carreira com foco social escolherá dedicar-se à gestão inovadora, resolvendo, nesse caso, o problema da inação. $\mathrm{Na}$ linguagem de desenho de mecanismos, a nova regra alinha os incentivos do gestor com os objetivos da Nova Gestão Pública. A proposição abaixo explicita esse resultado.

Proposição 2. Suponha que os parâmetros de preferências dos gestores ocupando cargos em DAS $\left(\alpha_{A}, \alpha_{B}\right)$ e das instituições ( $w_{C}, w_{P}, b_{S}$, $\left.b_{P} e \pi\right)$ satisfazem as Condições de Regularidade e as Condições de Incentivos Intermediários descritas na Proposição 1. Suponha ainda que, se os órgãos de controle identificarem conduta inovadora mas que resulta em benefício social por parte de um gestor, então esse gestor não será punido. Então os gestores que valorizam o bem-estar social se dedicarão a inovar em prol da sociedade, sejam eles temporários ou de carreira. 
A proposição acima garante que uma pequena alteração no ambiente legal é suficiente para garantir um maior engajamento dos servidores públicos que se preocupam com a sociedade na direção de uma gestão inovadora e eficiente. Vale lembrar, no entanto, que apesar de sua simplicidade teórica, esta alteração não é simples e envolve inclusive uma reinterpretação do Princípio da Legalidade, discutido anteriormente, à luz do também Princípio Constitucional da Eficiência. Apesar dessa dificuldade, tal proposta não se afigura irrealista. De fato, já existe ampla evidência na jurisprudência brasileira de situações em que o Princípio da Eficiência se sobrepôs ao Princípio da Legalidade, fazendo com que um Juiz julgue improcedentes processos impetrados com base nesse último princípio. Para uma discussão detalhada dessa jurisprudência, o leitor é convidado a ler Meneguin e Santos (2013).

Apesar de factível, uma tal alteração constitui ainda uma solução parcial para os problemas detectados, uma vez que ela não afeta os incentivos à corrupção por parte dos gestores privados evidenciados na seção anterior. Na próxima seção discutiremos como, adicionalmente, as instituições podem ser ajustadas de forma a coibir a corrupção.

\subsection{Compatibilizando os incentivos do gestor privado}

A supressão da punição vista anteriormente garante um bom comportamento por parte dos gestores sociais. No entanto, os incentivos aos gestores privados não são alterados no que diz respeito à comparação entre a inação e a corrupção. Portanto, dadas as CII, dentre os gestores temporários, aqueles que mais valorizam o retorno pessoal continuarão preferindo se corromper a adotar postura burocrática inativa.

E quanto ao investimento em bem-estar social? O que temos aqui é que o novo marco legal traz consigo um maior incentivo à gestão social também para esse gestor, pois sua utilidade nesse passa a ser $U\left(s ;\left(T, \alpha_{B}\right)\right)=w_{T}-\psi+\alpha_{B} b_{s}$. Portanto, temos agora dois incentivos conflitantes para esse gestor. Por um lado, ao corromper-se ganha mais com o benefício privado: $b_{p}>\alpha_{B} b_{s}$, por outro lado, seu salário esperado é menor: $w_{T}(1-\pi)<w_{T}$. Se as instituições investigativas 
estiverem suficientemente desenvolvidas de forma que a probabilidade de ser descoberto, $\pi$, é bastante elevada, então o efeito salário domina o efeito corrupção e o gestor que menos valora o benefício social também escolherá inovar em prol da sociedade.

Trata-se do melhor equilíbrio possível, pois apenas se acabando com a punição aos gestores sociais ganha-se também, como efeito adicional, o controle do comportamento do gestor privado. Vale ainda observar que, ao se acabar com a punição aos gestores sociais, acaba-se também com a inação dos gestores de carreira, uma vez que a dedicação ao social lhes gera também maior utilidade. Além disso, se os gestores temporários não tiverem incentivo à corrupção, tampouco terão os gestores de carreira, que têm mais a perder com a punição à corrupção.

Os resultados discutidos acima se encontram sumariados na proposição abaixo.

Proposição 3. Suponha que os parâmetros de preferências dos gestores ocupando cargos em DAS $\left(\alpha_{A}, \alpha_{B}\right)$ e das instituições $\left(w_{C}, w_{P}, b_{S}\right.$, $\left.b_{P} e \pi\right)$ satisfazem as Condições de Regularidade e as Condições de Incentivos Intermediários descritas na Proposição 1 e que, caso os órgãos de controle identifiquem conduta inovadora mas que resulta em benefício social por parte de um gestor, então esse gestor não será punido, como na Proposição 2. Suponha ainda que vale a Condição de Consolidação Institucional abaixo descrita.

(CCI) Condição de Consolidação Institucional:

$$
\text { (v) } \pi w_{T} \geq b_{p}+\alpha_{B} b_{s}
$$

Então todos os gestores públicos optarão por inovar em prol da sociedade, sejam eles de carreira ou temporários, que valorizam o bem -estar social ou privado.

Demonstração. Primeiramente, verifiquemos que o gestor temporário do tipo $\alpha_{\mathrm{B}}$ terá incentivo a se dedicar ao bem-estar social.

Caso escolha s sua utilidade será: $U\left(s ;\left(G, \alpha_{B}\right)\right)=w_{G}-\psi+\alpha_{B} b_{s}$. Caso escolha p sua utilidade será: $U\left(p ;\left(G, \alpha_{B}\right)\right)=w_{T}(1-\pi)-\psi+b_{p}$. Portanto, o gestor escolherá s se $\pi w_{T} \geq b_{p}+\alpha_{B} b_{s}$, que é a CCI. 
Portanto, o gestor temporário que valoriza mais o retorno privado decidirá se dedicar ao bem-estar social. Considere agora o gestor de carreira que valoriza mais o retorno privado. Como $w_{T}<w_{C}$, então a CCI implica em $\pi w_{C} \geq b_{p}+\alpha_{B} b_{s}$, o que, por sua vez, garante que esse gestor tem ainda maior incentivo em dedicar-se à inovação em prol do social, o que conclui a demonstração.

A Proposição 3 descreve uma situação ideal em que, com a ausência de punição aos gestores sociais inovadores, as instituições de controle são tão eficientes que o risco de ser descoberto em gestão corrupta é grande o suficiente para garantir que todo gestor se dedicará ao bem-estar social. No entanto, a existência de corrupção mesmo entre gestores de países com instituições de controle mais estabelecidas sugere que essa situação talvez ainda não seja uma realidade.

O que poderia então fazer um país em que a Condição de Consolidação Institucional (v) não seja satisfeita? Em primeiro lugar, é importante observar que mesmo que a CCI não seja satisfeita, a não punibilidade do gestor que escolher $s$ garante que nenhum gestor escolherá a inação $n$. Como vimos, os gestores sociais, de carreira ou temporários, ambos escolherão $s$. Já os gestores privados de carreira passarão a escolher $s$ enquanto os gestores privados temporários escolherão $p$ caso CCI não seja satisfeita. Nesse caso, para evitar a opção pela corrupção dos gestores temporários que valorizam mais o privado, o marco legal deverá tornar a dedicação em prol da sociedade ainda mais vantajosa para o gestor público, de forma a contrabalançar a tentação da corrupção. Uma forma de se fazer isso é premiar o gestor quando, ao se descobrir gestão inovadora, for verificado o benefício social do mesmo. Há, naturalmente, um custo para o governo envolvido nesse novo mecanismo. Esse custo, correspondendo à premiação que denotaremos por $l$, será calculado a seguir.

Para que um gestor temporário do tipo privado seja desestimulado a investir em atividade corrupta é necessário que a condição abaixo seja satisfeita.

$$
U\left(s ;\left(T, \alpha_{B}\right)\right)+\pi l \geq U\left(p ;\left(G, \alpha_{B}\right)\right)
$$

O que pode ser reescrito na forma abaixo:

$$
\pi\left(w_{T}+l\right) \geq b_{p}-\alpha_{B} b_{s}
$$


$\mathrm{Na}$ expressão acima, o ganho esperado com o prêmio deve ser suficiente para compensar a perda esperada com o investimento social vis-à-vis à corrupção. Como o governo deseja minimizar o custo, para disciplinar o gestor, escolherá o menor valor possível para $l$, que é dado pela expressão a seguir.

$$
l=\frac{b_{p}-\alpha_{B} b_{s}-\pi w_{T}}{\pi}
$$

A Proposição 4 abaixo sumaria a análise pregressa.

Proposição 4. Suponha que os parâmetros de preferências dos gestores ocupando cargos em DAS $\left(\alpha \alpha_{A}, \alpha_{B}\right)$ e das instituições ( $w_{C}, w_{P}, b_{S}, b_{P}$ $e \pi$ ) satisfazem as Condições de Regularidade e as Condições de Incentivos Intermediários descritas na Proposição 1, mas que não vale a Condição de Consolidação Institucional descrita na Proposição 3. Suponha ainda que, no caso em que os órgãos de controle identifiquem conduta inovadora mas que resulta em benefício social por parte de um gestor, então esse gestor não somente não será punido, como também receberá o prêmio à inovação dado pela expressão abaixo.

$$
\text { (vi) } l=\frac{b_{p}-\alpha_{B} b_{s}-\pi w_{T}}{\pi}
$$

Então, todos os gestores públicos optarão por inovar em prol da sociedade, sejam eles de carreira ou temporários, que valorizam o bem-estar social ou privado.

É importante notar que a Proposição 4 é um mecanismo bastante ousado em que o resultado de uma investigação pode ser não somente a ausência de punição, mas também uma premiação, ao se evidenciar benefício social da gestão inovadora. Observe novamente o papel da consolidação institucional: quanto maior for o valor do parâmetro $\pi$, menor será o custo de implantação desse mecanismo para o governo. Note ainda que existem várias formas de se implantar essa premiação, algumas das quais podem ser comparadas aos prêmios por produtividade que tem se tornado mais frequentes recentemente no setor público brasileiro. 


\section{Conclusão}

Este estudo discutiu como as instituições, normas legais e órgãos de controle do setor público podem modelar o comportamento dos gestores públicos, com importantes consequências para a eficiência da administração pública.

No modelo teórico construído, o gestor pode decidir: acomodar-se em comportamento burocrático de pouco benefício social; tornar-se mais ousado em suas ações de forma a melhorar a aplicação das políticas públicas gerando maior retorno social; ou se corromper visando aumentar seu retorno privado. Mostrou-se que os gestores que são servidores públicos estáveis têm incentivos a se enquadrar na categoria dos que se acomodam; não se corrompem, mas pouco fazem para tentar inovar. Em contrapartida, os gestores públicos que não são de carreira estariam mais dispostos a ousar; no entanto, essa ousadia extra pode ser canalizada tanto para benefício próprio (corrupção), quanto para a melhoria do serviço público (gestor imbuído de um maior espírito social).

Essas conclusões foram preliminarmente testadas por meio de modelos econométricos, envolvendo o método de regressão em painéis com efeitos aleatórios, nos quais se reforçou o resultado de que quanto maior o percentual de servidores de carreira ocupando os cargos de DAS em determinado ministério, menor é o número de tomadas de contas especiais instauradas por unidade (bilhão de reais correntes) de despesa executada, ou seja, menor é o número de irregularidades encontradas. Apesar desse resultado também se manifestar em modelo de mínimos quadrados empilhados (POLS), o resultado se perdeu quando foi considerado o método de regressão em painéis com efeitos fixos, sugerindo a necessidade de estudos econométricos mais aprofundados para se testar com mais robustez a relação preliminarmente encontrada.

Um aspecto importante do modelo estudado, e que reflete a realidade, é que desvios da regra legal tendem a ser tratados com a mesma severidade, caso descobertos, sendo eles motivados por corrupção, portanto nocivo à coisa pública, ou por desejo de melhorar o resultado social das políticas públicas. Esse aspecto sugere a análise de como as instituições podem ser alteradas de forma a gerar melhores equilíbrios sociais, o que foi feito lançando mão da teoria de dese- 
nhos de mecanismos. O primeiro resultado obtido foi que quando se retira a punição ex-post para o caso de haver promoção de bem público, o gestor que atribui valor elevado à contribuição social preferirá ousar em prol da sociedade, não havendo mais inação.

Essa alteração institucional induz o fim da inação por parte dos gestores públicos voltados para o social. Não se trata, no entanto, de mudança simples, pois envolve uma reinterpretação da Constituição com foco no Princípio da Eficiência. Meneguin e Santos (2013) apresentam cuidadosa análise sobre os conflitos entre os princípios constitucionais da Legalidade e da Eficiência mostrando, por meio de estudos de casos, que, de fato, já existem inúmeros exemplos na Justiça Federal e no Tribunal de Contas, em que se optou por privilegiar a eficiência em detrimento da legalidade. Destarte, a proposta apresentada se caracteriza por viável, ainda que não simples.

No entanto, dentre os gestores que têm por interesse principal o benefício privado, aqueles que ocupam cargos temporários poderão ainda preferir se dedicar a atividades corruptas. Para resolver esse problema, o governo terá que, além de não punir, oferecer uma premiação adequada para aqueles gestores que, após investigados, resulta evidenciado que sua conduta inovadora contribuiu para o bem-estar social. Caso esse último mecanismo seja implantado, não somente acabar-se-á com a inação, como também será aberto caminho para um melhor alinhamento dos incentivos no sentido de se coibir a corrupção.

Note que, ainda que a esta última modificação institucional -mais ousada e custosa- de premiar o gestor inovador não seja adotada, o fim da punição quando sua inovação beneficia a sociedade pode resultar em maior engajamento de grande parte do corpo de gestores públicos. Mais ainda, pode contribuir para uma melhor seleção de gestores públicos a médio prazo, por meio de autosseleção, ou seja, aqueles cidadãos que mais valoram o retorno privado tenderão a se distanciar naturalmente do setor público, enquanto aqueles cidadãos que mais valoram o bem-estar social se sentirão ainda mais atraídos pela carreira pública.

Esses resultados sugerem algumas reflexões sobre a direção que devem tomar as políticas públicas. A primeira delas é que se deve pensar em maneiras para motivar o servidor de carreira, incenti- 
vando-o a tomar ações que propiciem melhoras na administração pública. Fernandes (1999) enfatiza a necessidade de treinamento, ao argumentar que "não se pode conceber que sejam encarregados de dar cumprimento a uma legislação complexa servidores sem prévio conhecimento do assunto, normalmente já sobrecarregados de tarefas múltiplas". Nesse sentido, seria extremamente salutar uma maior interação entre órgãos de controle, como Controladoria-Geral, Tribunal de Contas, Ministério Público e o restante da administração pública.

No que diz respeito à rigidez da legislação, a principal contribuição do modelo teórico de incentivos aqui estudado é que, se por um lado, o Brasil encontra-se no caminho certo ao reforçar o controle do gasto público, por outro lado, maior abertura e flexibilização à atuação do gestor, permitindo que este comprove o resultado socialmente superior de certas condutas não previstas originalmente na norma legal, podem trazer grandes benefícios à sociedade. Inicialmente, tal flexibilização estimularia gestores honestos a inovarem sem medo de serem futuramente punidos pela inovação. Como consequência, mais gestões honestas inovando em prol do bem estar social significam melhores resultados com o mesmo orçamento, gerando, portanto, aplicação mais eficiente dos recursos públicos. Nesse sentido, os achados deste trabalho contribuem para a literatura conhecida por "Nova Gestão Pública".

Por fim, tem-se o problema do atual modo de preenchimento dos cargos de DAS. Em vez de se adotar critérios políticos, o ideal é que essas funções sejam preenchidas com base em mérito, sem que se perda a flexibilidade na contratação. Poderia se pensar em um comitê de seleção que anunciaria a disponibilidade da vaga e os requisitos para preenchê-la (entrevistas, currículo, cartas de apresentação de antigos superiores hierárquicos, etc., vide Mendes, 2011). Isso possibilitaria a descoberta de talentos dentro e fora da administração pública, incentivando o aprimoramento constante e a maior profissionalização dos quadros.

A principal contribuição deste estudo é, portanto, explicitar os incentivos que definem o comportamento dos gestores públicos. Espera-se que tais considerações sejam contempladas nas discussões de políticas públicas que tenham por objetivo tornar o serviço público mais profissional e eficiente, fazendo com que o Estado melhore 
seu atendimento à sociedade. Este trabalho ainda suscita diversos questionamentos que podem ser explorados em pesquisas futuras. Em primeiro lugar, apesar dos resultados preliminares do estudo econométrico confirmarem a previsão teórica, fica em aberto o desafio de se buscar variáveis que melhor possam medir a tomada de decisões ilegais no serviço público, além das TCE's. Estudo futuro poderia explorar outros tipos de processos administrativos. Poderiam ainda aprofundar a análise das TCE's com vistas a melhor discernir e tipificar o ato ilegal associado a cada uma delas, de forma a poder se caracterizar o ato inovador em prol da sociedade, diferenciando-o do ato ilegal em benefício próprio do gestor público. Mais geralmente, há ainda o desafio de se encontrar uma medida explícita da gestão inovadora em cada ministério brasileiro, de forma a se medir o outro efeito associado à maior participação de gestores externos à carreira nos cargos de DAS. Esse efeito, também previsto pelo modelo teórico, não pode ainda ser testado pela ausência, até o momento, de uma variável adequada. Portanto, a extensão do estudo econométrico com vistas a se incluir os efeitos positivos da participação externa na administração pública é deixada aqui como uma sugestão para pesquisas futuras.

Finalmente, o estudo feito a nível federal poderia ser expandido para os governos subnacionais de forma a se testar se existe relação no âmbito dos estados, por exemplo, entre a participação de funcionários externos à carreira pública em posições gerencias e a ocorrência de escândalos de corrupção e/ou inovações gerenciais.

\section{Referências}

ABRUCIO, F. L. Trajetória recente da gestão pública brasileira: um balanço crítico e a renovação da agenda de reformas. Revista Brasileira de Administração Pública, v. 1, p. 77-87, 2007.

BARDHAN, P. Corruption and development: A review of issues. Journal of Economic Literature, 35 , 1320-1346, 1997.

BRIGNALL, S.; MODELL, S. An institutional perspective on performance measurement and management in the 'new public sector'. Management Accounting Research, 11: 281-306, 2000.

BUGARIN, M.; VIEIRA, L. Benefit Sharing: An Incentive Mechanism for Social Control of Government Expenditure. Quarterly Review of Economics and Finance, 48: 673-690, 2008.

CÂNDIDO JR., J. O. Os gastos públicos no Brasil são produtivos? Planejamento e Políticas Públicas, 23: 233-260, 2001. 
CASTRO, R. V. Análise Econômica do Direito e Fiança Locatícia. 2011. 126 p. Dissertação (Mestrado). Direito - PUC/MG, Belo Horizonte, 2011.

DRISCOLL, J.; KRAAY, A. Consistent covariance matrix estimation with spatially dependent data. Review of Economics and Statistics 80: 549-560, 1998.

ESTADÃO. Ouça as gravações da PF sobre o escândalo do ministério do Turismo, 12/09/2011.

FERNANDES, J. U. J. A Qualidade na Lei de Licitações - o equívoco de comprar pelo menor preço, sem garantir a qualidade. BLC-Boletim de Licitações e Contratos, 12 (2): 71-83, 1999.

FOLHA DE SÃO PAULO. Suspeita no Esporte envolve cúpula do governo do DF, 1/11/2011.

HABIB, M.; ZURAWICKI, L. Corruption and foreign direct investment. Journal of International Business Studies, 33, 291-307, 2002.

HOECHLE, D. Robust standard errors for panel regressions with cross-sectional dependence. The Stata Journal, 7(3):281-312, 2007.

HOEPERS, B. Politicization, Political Appointments, and Corruption in Brazilian Federal Ministries. Pesquisa apresentada no "Thirty Years of Democracy in Brazil: A Research Workshop", Notre Dame University, IN, EUA, 20 de abril de 2015.

HOOD, C. The 'New Public Management' in the 1980s: Variations on a theme. Accounting, Organizations and Society, 20(2/3): 93-109, 1995.

HUNTINGTON, S. P. Political Order in Changing Societies. New Haven: Yale Univ. Press, 1968.

LOPEZ, F.; BUGARIN, M.; BUGARIN, K. Rotatividade nos Cargos de Confiança da Administração Federal Brasileira (1999-2013). Revista do Serviço Público, 65(4): 439-461, 2014.

LOPEZ, F.; BUGARIN, M.; BUGARIN, K. Mudança Político-Partidária e Rotatividade nos Cargos de Confiança (1999-2013), in: LOPEZ, F. (ed.): Cargos de Confiança e o Presidencialismo de Coalizão no Brasil. Brasília: IPEA, 2015. 33-70.

MAURO, P. Corruption and Growth. The Quarterly Journal of Economics, 110 (3): 681-712, 1995.

MENDES, M. Política de Pessoal do Governo Federal: diretrizes para maior produtividade, qualidade, economicidade e igualdade. In: Meneguin, F. B. Agenda Legislativa para o Desenvolvimento Nacional. Brasília: Senado Federal, Subsecretaria de Edições Técnicas, 2011.

MENEGUIN, F. B.; SANTOS, P. F. O. Há Incompatibilidade entre Legalidade e Eficiência? Brasília: Núcleo de Estudos e Pesquisas/CONLEG/Senado, ago/2013 (Texto para Discussão n 133). Disponível em: www.senado.leg.br/estudos. Acesso em 14 dez 2014.

NORTH, D. C. Institutions, institutional change and economic performance. Cambridge: Cambridge University Press, 1990.

PERRY, J.; WISE, L. The Motivational Bases of Public Service. Public Administration Review, 50(3): 367-373, 1990.

POLlitT, C.; VON THIEL, S.; HOMBURG, V. New Public Management in Europe. Management Online Review, 1-6, 2007.

PRAIS, S.; WINSTEN, C. Trend Estimators and Serial Correlation. Cowles Commission Discussion Paper No. 383, 1954.

ROEMER, A. Introducción al análisis económico del derecho. México: Fondo de Cultura Económica, terceira edição, 2001.

SOSA-ESCUDERO, W.; BERA, A. Tests for unbalanced error-components models under local misspecification. The Stata Journal, 8(1):68-78, 2008.

TANZI, V. Corruption around the world: causes, consequences, scopes and cures. IMF Staff Papers, 45 (4): 559-594, 1998.

VON HAGEN, J. Fiscal Rules, Fiscal Institutions, and Fiscal Performance. The Economic and Social Review, 33(3): 263-284, 2002. 
VIEIRA, L., BUGARIN, M.; GARCIA, L. Benefícios compartilhados: um mecanismo para induzir a participação da sociedade no controle dos gastos públicos no Brasil. Economia Aplicada, 8(1): 1-24, 2004.

ZUCCO JR., C. "Esquerda, direita e governo: a ideologia dos partidos políticos brasileiros”, em: ZUCCO JR., C. \& POWER, T. O Congresso por ele mesmo: auto percepções da classe política brasileira. Belo Horizonte: Humanitas, 2011.

ZUCCO JR., C. "The Ideology of Brazilian Parties: Technical Notes on the Third Edition of Estimates". Mimeo. 10 de janeiro de 2014.

\section{Apêndice}

\section{A1. Estimativas de ideologia partidária e presidencial}

Tabela Al- Estimativas da ideologia partidária

\begin{tabular}{|c|c|c|c|c|c|c|c|c|c|c|c|c|c|c|c|c|c|}
\hline \multirow{2}{*}{ Partido } & \multicolumn{17}{|c|}{ Ano } \\
\hline & 1997 & 1998 & 1999 & 2000 & 2001 & 2002 & 2003 & 2004 & 2005 & 2006 & 2007 & 2008 & 2009 & 2010 & 2011 & 2012 & 2013 \\
\hline PCdoB & 1,53 & 1,60 & 1,66 & 1,73 & 1,79 & 1,92 & 2,06 & 2,19 & 2,32 & 2,31 & 2,31 & 2,30 & 2,29 & 2,30 & 2,30 & 2,31 & 2,31 \\
\hline PDS, PP & 7,09 & 7,07 & 7,05 & 7,03 & 7,01 & 6,93 & 6,85 & 6,76 & 6,68 & 6,56 & 6,45 & 6,33 & 6,21 & 6,26 & 6,31 & 6,35 & 6,40 \\
\hline PDT & 2,84 & 2,90 & 2,95 & 3,01 & 3,06 & 3,18 & 3,30 & 3,41 & 3,53 & 3,50 & 3,47 & 3,43 & 3,40 & 3,43 & 3,46 & 3,49 & 3,52 \\
\hline PFL, DEM & 6,90 & 6,87 & 6,84 & 6,80 & 6,77 & 6,74 & 6,71 & 6,67 & 6,64 & 6,60 & 6,56 & 6,52 & 6,48 & 6,61 & 6,74 & 6,87 & 7,00 \\
\hline PMDB & 4,69 & 4,78 & 4,86 & 4,95 & 5,03 & 5,04 & 5,05 & 5,05 & 5,06 & 4,98 & 4,89 & 4,81 & 4,72 & 4,81 & 4,89 & 4,98 & 5,06 \\
\hline PSB & 2,48 & 2,52 & 2,55 & 2,59 & 2,62 & 2,70 & 2,79 & 2,87 & 2,95 & 2,98 & 3,01 & 3,03 & 3,06 & 3,08 & 3,09 & 3,11 & 3,12 \\
\hline PSD & & & & & & & & & & & & & & & & & 5,68 \\
\hline PSDB & 4,98 & 5,01 & 5,04 & 5,07 & 5,10 & 5,05 & 5,00 & 4,95 & 4,90 & 4,87 & 4,83 & 4,80 & 4,76 & 4,86 & 4,97 & 5,07 & 5,17 \\
\hline $\begin{array}{l}\text { PR, PL, } \\
\text { PRB }\end{array}$ & 6,44 & 6,30 & 6,17 & 6,03 & 5,89 & 5,92 & 5,95 & 5,97 & 6,00 & 5,90 & 5,80 & 5,70 & 5,60 & 5,65 & 5,70 & 5,74 & 5,79 \\
\hline PT & 1,78 & 1,87 & 1,96 & 2,04 & 2,13 & 2,36 & 2,59 & 2,81 & 3,04 & 3,01 & 2,98 & 2,94 & 2,91 & 2,92 & 2,93 & 2,94 & 2,95 \\
\hline PV & - & & & & - & & & & - & & & & 3,74 & 3,77 & 3,81 & 3,84 & 3,87 \\
\hline Dilma & & & & & & & & & & & & & & & & & 3,42 \\
\hline Lula & & & & & & & & & & & & & & & & & 3,24 \\
\hline $\mathrm{FHC}$ & & & & & & & & & & & & & & & & & 4,98 \\
\hline
\end{tabular}

Fonte: Lopez, Bugarin e Bugarin (2015).

Obs.: Os valores destacados em itálico correspondem às estimativas em Zucco, Jr. (2014) e os demais, às interpolações efetuadas em Lopez, Bugarin e Bugarin (2015). Foi usada interpolação linear simples para anos não explicitados nessa classificação, usando para tanto os dois anos mais próximos, sendo usados pesos para refletir a proximidade dos anos extremos do intervalo considerado com o ano em questão. Nos casos em que o ministro no cargo não possuía filiação partidária optamos por classificar sua ideologia como aquela atribuída ao presidente. Essa escolha reflete o fato de que a seleção de um ministro sem partido indica que o/a presidente não negociou com partidos para sua tomada de decisão. No ano em que houve mudança partidária, tomou-se a ideologia do ministro entrante.

No presente estudo foram usadas apenas as estimativas referentes ao período 2002-2013. 


\section{A2. Teste de Chow para efeitos fixos}

O objetivo deste teste é determinar se uma regressão por meio do método dos mínimos quadrados empilhados se adequa bem aos dados ou se é mais adequado o uso da regressão em painéis com efeitos fixos. Os resultados abaixo sugerem fortemente que o uso da metodologia de painéis com efeitos fixos é vantajoso.

Tabela A2 - Teste de especificação de Chow

\begin{tabular}{c|c|c|c}
\hline Modelo & 1 & 2 & 3 \\
\hline $\mathrm{F}$ & $\mathrm{F}(23,216)$ & $\mathrm{F}(21,213)$ & $\mathrm{F}(21,210)$ \\
\hline Estatística $F$ & 3,99 & 4,13 & 4,61 \\
\hline$p$-valor & $<10^{-4}$ & $<10^{-4}$ & $<10^{-4}$ \\
\hline
\end{tabular}

Fonte: Elaboração dos autores.

\section{A3. Teste do Multiplicador de Lagrange de Breusch e Pagan para efeitos aleatórios}

O objetivo deste teste é determinar se uma regressão por meio do método dos mínimos quadrados empilhados se adequa bem aos dados ou se é mais adequado o uso da regressão em painéis com efeitos aleatórios. Os resultados abaixo sugerem fortemente que o uso da metodologia de painéis com efeitos aleatórios é vantajoso.

Tabela A3 - Estatístico do Teste ML de Breusch e Pagan

\begin{tabular}{cc|c|c}
\hline Modelo & 1 & 2 & 3 \\
\hline Estatístico $\chi^{2}(1)$ & 45,78 & 17,87 & 21,60 \\
\hline$p$-valor & $<10^{-4}$ & $<10^{-4}$ & $<10^{-4}$ \\
\hline
\end{tabular}

Fonte: Cálculos dos autores

\section{A4. Teste de Hausman}

O objetivo deste teste é indicar qual dos dois tipos de regressão em painéis, a de efeitos fixos ou a de efeitos aleatórios, melhor se adequa aos dados analisados. Os resultados abaixo sugerem que para todos os modelos os efeitos aleatórios devem ser usados.

Tabela A4 - Teste de Hausman para painéis com efeitos fixos \& efeitos aleatórios

\begin{tabular}{cc|c|c}
\hline Modelo & 1 & 2 & 3 \\
\hline Graus de liberdade $k$ & 12 & 15 & 18 \\
\hline Estatístico $\chi^{2}(k)$ & 6,10 & 10,26 & 17,72 \\
\hline$p$-valor & 0,9109 & 0,8030 & 0,4741 \\
\hline
\end{tabular}

Fonte: Cálculos dos autores 


\section{A5. Teste de Quociente de Verossimilhança}

O objetivo deste teste é verificar a existência de heterocedasticidade nos modelos estudados. Para tanto, foram rodadas duas regressões pelo método dos mínimos quadrados generalizados, sendo a primeira com a opção de controle por heterocedasticidade em painéis. Os resultados, apresentados na tabela abaixo, sugerem a clara presença de heterocedasticidade em todos os modelos.

Tabela A5 - Teste de quociente de verossimilhança para painéis com efeitos aleatórios

\begin{tabular}{cc|c|c} 
Graus de liberdade: $\boldsymbol{k}=\mathbf{2 1}$ \\
\hline Modelo & 1 & 2 & 3 \\
\hline Estatístico $\chi^{2}(k)$ & 989,93 & 974,11 & 955,35 \\
\hline$p_{\text {-valor }}$ & $<10^{-4}$ & $<10^{-4}$ & $<10^{-4}$ \\
\hline
\end{tabular}

Fonte: Cálculos dos autores

\section{A6. Teste de Wooldridge}

O objetivo deste teste é verificar a existência de autocorrelação nos modelos estudados. A Tabela A6 a seguir apresenta os resultados obtidos para cada modelo, sugerindo a presença de autocorrelação para todos os modelos.

Tabela A6 - Teste de Wooldridge autocorrelação em painéis

Graus de liberdade: $k=21$

\begin{tabular}{cc|c|c}
\hline Modelo & 1 & 2 & 3 \\
\hline Estatístico $F(1, k)$ & 3,642 & 3,609 & 3,698 \\
\hline$p$-valor & 0.0701 & 0,0713 & 0,0682 \\
\hline
\end{tabular}

Fonte: Cálculos dos autores

\section{A7. Regressões em Painéis com Efeitos Aleatórios: Os três mode- los completos}

A Tabela A6 a seguir apresenta os detalhes das três regressões em painéis com efeitos aleatórios e erros pardrões de Prais-Winsten. Duas linhas estão associadas a cada variável para cada modelo. $\mathrm{Na}$ primeira linha estão o coeficiente estimado e seu nível de significância. Na segunda linha, entre parênteses, se encontra a estatística $z$ e entre colchetes o $p$-valor. 
Tabela A7 - Painéis com efeitos aleatórios e erros padrões de Prais-Winsten

Variável dependente - Número de TCE’s por bilhão de gasto executado

(estatístico $z$ ) [ $p$-valor]

\begin{tabular}{|c|c|c|c|c|c|c|}
\hline Variáveis explicativas & \multicolumn{2}{|c|}{ Modelo 1} & \multicolumn{2}{|c|}{ Modelo 2} & \multicolumn{2}{|c|}{ Modelo 3} \\
\hline Constante & $\begin{array}{l}57,57 \\
(1,92)\end{array}$ & $\begin{array}{l} \\
{[0,054]}\end{array}$ & $\begin{array}{l}76,48 \\
(2.97)\end{array}$ & $\begin{array}{l}* * * \\
{[0,003]}\end{array}$ & $\begin{array}{l}69,41 \\
(2.37)\end{array}$ & $\begin{array}{l}* \\
{[0,018]}\end{array}$ \\
\hline Carreira & $\begin{array}{l}-73,12 \\
(-1,70)\end{array}$ & $\begin{array}{l}* \\
{[0,089]}\end{array}$ & $\begin{array}{l}-71.51 \\
(-1,96)\end{array}$ & $\begin{array}{l}* \star \\
{[0,050]}\end{array}$ & $\begin{array}{l}-74,60 \\
(-2,10)\end{array}$ & $\begin{array}{l}* * \\
{[0,036]}\end{array}$ \\
\hline D03 & $\begin{array}{r}-2,35 \\
(-0,63)\end{array}$ & {$[0,526]$} & $\begin{array}{r}-4,65 \\
(-1,15)\end{array}$ & {$[0,251]$} & $\begin{array}{r}3,09 \\
0,42)\end{array}$ & {$[0,676]$} \\
\hline D04 & $\begin{array}{r}-6,35 \\
(-0,98)\end{array}$ & {$[0,325]$} & $\begin{array}{r}-8,20 \\
(-1,26)\end{array}$ & {$[0,209]$} & $\begin{array}{r}-3,34 \\
(-0,44)\end{array}$ & {$[0,663]$} \\
\hline D05 & $\begin{array}{r}-1,73 \\
(-0,23)\end{array}$ & {$[0,820]$} & $\begin{array}{r}-3,24 \\
(-0,43) \\
\end{array}$ & {$[0,668]$} & $\begin{array}{r}0,71 \\
(0,09) \\
\end{array}$ & {$[0,930]$} \\
\hline D06 & $\begin{array}{r}-4,25 \\
(-0,49) \\
\end{array}$ & {$[0,623]$} & $\begin{array}{r}-6,02 \\
(-0,72) \\
\end{array}$ & {$[0,472]$} & $\begin{array}{r}-2,15 \\
(-0,24) \\
\end{array}$ & {$[0,809]$} \\
\hline D07 & $\begin{array}{r}-5,32 \\
(-0,57)\end{array}$ & {$[0,571]$} & $\begin{array}{r}-6,94 \\
(-0,78)\end{array}$ & {$[0,435]$} & $\begin{array}{r}-3,11 \\
(-0.33)\end{array}$ & {$[0,739]$} \\
\hline D08 & $\begin{array}{r}-5,83 \\
(-0,59) \\
\end{array}$ & {$[0,558]$} & $\begin{array}{r}-7,16 \\
(-0,77) \\
\end{array}$ & {$[0,439]$} & $\begin{array}{r}-3,57 \\
(-0.37) \\
\end{array}$ & {$[0,709]$} \\
\hline D09 & $\begin{array}{r}-5,54 \\
(-0,53)\end{array}$ & {$[0,594]$} & $\begin{array}{r}-6,59 \\
(-0,69)\end{array}$ & {$[0,490]$} & $\begin{array}{r}-2,37 \\
(-0,24)\end{array}$ & {$[0,813]$} \\
\hline D10 & $\begin{array}{r}-5,33 \\
(-0,49)\end{array}$ & {$[0,622]$} & $\begin{array}{r}-6,32 \\
(-0.65)\end{array}$ & {$[0,518]$} & $\begin{array}{r}-2,84 \\
(-0,29)\end{array}$ & {$[0,774]$} \\
\hline D11 & $\begin{array}{r}-3,28 \\
(-0,29) \\
\end{array}$ & {$[0,769]$} & $\begin{array}{r}-4,53 \\
(-0,45) \\
\end{array}$ & {$[0,649]$} & $\begin{array}{r}-1,51 \\
(-0,14)\end{array}$ & {$[0,889]$} \\
\hline D12 & $\begin{array}{r}5,58 \\
(0,49) \\
\end{array}$ & {$[0,626]$} & $\begin{array}{r}4,50 \\
(0,45) \\
\end{array}$ & {$[0,654]$} & $\begin{array}{r}7,92 \\
(0.72) \\
\end{array}$ & {$[0,469]$} \\
\hline D13 & $\begin{array}{r}22,89 \\
(1,96) \\
\end{array}$ & $\begin{array}{l}* * \\
{[0,050]}\end{array}$ & $\begin{array}{l}21,87 \\
(2,17) \\
\end{array}$ & $\begin{array}{l}\text { ** } \\
{[0,030]}\end{array}$ & $\begin{array}{l}25,55 \\
(2,32) \\
\end{array}$ & $\begin{array}{l}* * \\
{[0,020]}\end{array}$ \\
\hline Gasto executado & & & $\begin{array}{r}0,01 \\
(0,43)\end{array}$ & {$[0,665]$} & $\begin{array}{r}0,01 \\
(0,40)\end{array}$ & {$[0,685]$} \\
\hline DAS & & & $\begin{array}{r}-0,16 \\
(-2,27) \\
\end{array}$ & $\begin{array}{l}* * \\
{[0,023]}\end{array}$ & $\begin{array}{r}-0,14 \\
(-2,13) \\
\end{array}$ & {$[0,033]$} \\
\hline Servidores & & & $\begin{array}{r}-0,35 \\
(-0,28) \\
\end{array}$ & {$[0,777]$} & $\begin{array}{r}-0,43 \\
(-0,35) \\
\end{array}$ & {$[0,727]$} \\
\hline Ministério Novo & & & $\begin{array}{r}-2,64 \\
(-0,10)\end{array}$ & {$[0,918]$} & $\begin{array}{r}-2,92 \\
(-0,11)\end{array}$ & {$[0,909]$} \\
\hline Controle & & & $\begin{array}{r}9,43 \\
(0,38)\end{array}$ & {$[0,707]$} & $\begin{array}{r}9,46 \\
(0,39)\end{array}$ & {$[0,696]$} \\
\hline Social & & & $\begin{array}{r}-3,34 \\
(-0,16) \\
\end{array}$ & {$[0,872]$} & $\begin{array}{r}-1,41 \\
(-0,07)\end{array}$ & {$[0,945]$} \\
\hline Infraestrutura & & & $\begin{array}{l}-28,88 \\
(-3,15)\end{array}$ & $\begin{array}{l}* * * \\
{[0,002]}\end{array}$ & $\begin{array}{r}-31,31 \\
(-3.42) \\
\end{array}$ & $\begin{array}{l}* * * \\
{[0,001]}\end{array}$ \\
\hline Ideologia & & & & & $\begin{array}{r}2,12 \\
(0,96) \\
\end{array}$ & {$[0,335]$} \\
\hline Mudança ministro & & & & & $\begin{array}{r}2,63 \\
(0,89) \\
\end{array}$ & {$[0,374]$} \\
\hline Rotatividade de DAS & & & & & $\begin{array}{r}-0,15 \\
(-0.70) \\
\end{array}$ & {$[0,485]$} \\
\hline$R^{2}$ & 8,39 & & 12,01 & & 12,75 & \\
\hline
\end{tabular}

Número de observações: 250. Número de grupos: 22.

***: Estatisticamente significante ao nível de significância de 1\%

**: Estatisticamente significante ao nível de significância de 5\%

*: Estatisticamente significante ao nível de significância de $\quad 10 \%$

Fonte: Cálculos dos autores. 


\section{A8. Método dos Mínimos Quadrados Empilhados e Painéis com Efeitos Fixos}

Para efeito de comparação, o método dos mínimos quadrados empilhados (MQE) e o método de painéis com efeitos fixos foram aplicados usando-se para tanto os estimadores de Driscoll \& Kraay (1998) que oferecem correção para heteroscedasticidade, autocorrelação dos resíduos do tipo $\mathrm{MA}(q)$ e correlação contemporânea. ${ }^{19}$ A Tabela A8.1 apresenta os resultados para o MQE.

Tabela A8.1 - Mínimos quadrados empilhados com erros padrões de Driscoll e Kaay

Variável dependente: Número de TCE's por bilhão de gasto executado (modelo reduzido)

\begin{tabular}{l|rlrrr}
\hline Variáveis explicativas & Coeficiente & & Erro padrão & Estatística $t$ & $p$-Valor \\
\hline Carreira & $-67,70$ & ${ }^{* *}$ & 26,59 & $-2,55$ & 0,027 \\
D13 & 24,80 & ${ }^{* * *}$ & 0,91 & 27,06 & 0,000 \\
DAS & $-0,004$ & & 0,002 & $-1,67$ & 0,133 \\
Infraestrutura & $-19,92$ & ${ }^{* * *}$ & 5,80 & $-3,43$ & 0,006 \\
Constante & 59,34 & ${ }^{* * *}$ & 17,99 & 3,30 & 0,007 \\
\hline Observações incluídas & 250 & & & \\
Número de grupos & 22 & & & \\
$\mathrm{R}^{2}$ & 17,76 & & \\
${ }^{* * *}$ : Estatisticamente significante ao nível de significância de 1\% & \\
${ }^{* *}$ : Estatisticamente significante ao nível de significância de 5\% & \\
${ }^{*}$ : Estatisticamente significante ao nível de significância de 10\% & \\
Fonte: Cálculos dos autores.
\end{tabular}

A Tabela A8.2 apresenta, por sua vez, os resultados para painéis com efeitos fixos, corrigidos pela mesma metodologia de Driscoll e Kaay.

Tabela A8.2 - Painéis de efeitos fixos com erros padrões de Driscoll e Kaay

Variável dependente: Número de TCE's por bilhão de gasto executado (modelo reduzido)

\begin{tabular}{|c|c|c|c|c|c|}
\hline Variáveis explicativas & Coeficiente & & Erro padrão & Estatística $t$ & $p$-Valor \\
\hline Carreira & 35,66 & & 26,06 & 1,37 & 0,199 \\
\hline D13 & 21,23 & $* * *$ & 2,35 & 9,03 & 0,000 \\
\hline DAS & $-0,02$ & $* * *$ & 0,007 & $-3,61$ & 0,004 \\
\hline Constante & 12,20 & & 12,33 & 0,99 & 0,344 \\
\hline Observações incluídas & 250 & & & & \\
\hline Número de grupos & 22 & & & & \\
\hline $\mathrm{R}^{2}$ & 5,56 & & & & \\
\hline
\end{tabular}

***: Estatisticamente significante ao nível de significância de 1\%

**: Estatisticamente significante ao nível de significância de 5\%

*: Estatisticamente significante ao nível de significância de 10\%

Fonte: Cálculos dos autores.

${ }^{19}$ Veja também Hoechle (2007). 


\section{A9. Teorema geral de incentivos institucionais à atuação do gestor público}

O principal resultado teórico deste trabalho, a Proposição 1, toma por base as Condições de Incentivos Intermediários. Essas condições provocam uma certa separação no comportamento dos servidores, de forma que aqueles que têm carreira com emprego seguro optam pela inação para garantir sua renda, enquanto aqueles que são temporários ousarão mais, tanto no sentido de maior eficiência social de suas ações, como no sentido de maior corrupção, a depender de seus respectivos tipos.

Nesta seção apresentamos e discutimos rapidamente as demais configurações dos parâmetros da sociedade e seus respectivos efeitos sobre as decisões dos servidores. ${ }^{20}$

Proposição A1. Suponha que os parâmetros de preferências dos gestores ocupando cargos em DAS $\left(\alpha_{A}, \alpha_{B}\right) e$ das instituições $\left(w_{C}, w_{P}, b_{S}\right.$, $\left.b_{P} e \pi\right)$ satisfazem as Condições de Regularidade abaixo.

(CR) Condições de Regularidade:

(i) $\alpha_{A}>1>\alpha_{B}$

(ii) $\alpha_{A} b_{S}>b_{P}>b_{S}$

Então, um dos seguintes casos deve necessariamente ocorrer.

Caso 1. As Condições de Incentivos Intermediários (CII) abaixo são satisfeitas.

(iii) $\pi w_{C}>\alpha_{A} b_{S}-\psi>\pi w_{T}$

(iv) $\pi w_{C}>b_{P}-\psi>\pi w_{T}$

Então os gestores de carreira optarão por não tomar quaisquer decisões que acarretem riscos, não se envolvendo em atividades corruptas, mas tampouco tomando decisões inovadoras que maximizem o retorno social das políticas por eles geridas. Além disso, os gestores temporários se arriscarão mais, tanto ao tomar medidas visando um melhor resultado social, para aqueles que valorizam o bem-estar so-

${ }^{20}$ Agradecemos a um parecerista anônimo pela sugestão de explorarmos mais cuidadosamente as diferentes alternativas. 
cial, quanto ao envolver-se em atividades corruptas visando o benefício pessoal, para os demais.

Caso 2. As Condições de Incentivos Fortes (CIF) abaixo são satisfeitas.

(v) $\pi w_{C}>\alpha_{A} b_{S}-\psi>\pi w_{T}$

(vi) $\pi w_{C}>\pi w_{T}>b_{P}-\psi$

Então apenas os gestores temporários do tipo social escolherão tomar decisões inovadoras. Os demais gestores de carreira e os temporários do tipo privado optarão pela atitude burocrática passiva.

Caso 3. As Condições de Incentivos Fracos (CIf) abaixo são satisfeitas.

$$
\begin{aligned}
& \text { (vii) } \alpha_{A} b_{S}-\psi>\pi w_{C}>\pi w_{T} \\
& \text { (viii) } \pi w_{C}>b_{P}-\psi>\pi w_{T}
\end{aligned}
$$

Então os gestores do tipo social, sejam eles de carreira ou temporários, escolherão tomar decisões inovadoras. Já os gestores do tipo privado, se de carreira, escolherão a inação e se temporários, a conduta corrupta.

Caso 4. As Condições de Incentivos Não-Ativos (CIN) abaixo são satisfeitas.

$$
\begin{aligned}
& \text { (ix) } \alpha_{A} b_{S}-\psi>\pi w_{C}>\pi w_{T} \\
& \text { (x) } b_{P}-\psi>\pi w_{C}>\pi w_{T}
\end{aligned}
$$

Então os gestores do tipo social, sejam eles de carreira ou temporários, escolherão tomar decisões inovadoras. Já os gestores do tipo privado, sejam eles de carreira ou privados, escolherão a conduta corrupta.

Caso 5. As Condições de Incentivos Sociais (CIS) abaixo são satisfeitas.

$$
\begin{aligned}
& \text { (xi) } \alpha_{A} b_{S}-\psi>\pi w_{C}>\pi w_{T} \\
& \text { (xii) } \pi w_{C}>\pi w_{T}>b_{P}-\psi
\end{aligned}
$$


Então os gestores do tipo social, sejam eles de carreira ou temporários, escolherão tomar decisões inovadoras. Já os gestores do tipo privado, sejam eles de carreira ou privados, escolherão a inação.

Caso 6. As Condições de Incentivos Rígidos (CIR) abaixo são satisfeitas.

$$
\begin{aligned}
& \text { (xiii) } \pi w_{C}>\pi w_{T}>\alpha_{A} b_{S}-\psi \\
& \text { (xiv) } \pi w_{C}>\pi w_{T}>b_{P}-\psi
\end{aligned}
$$

Então todos os gestores, quaisquer que sejam seus tipos ou carreira, escolherão a inação.

O Caso 1 já foi discutido anteriormente no texto e corresponde à situação em que as instituições exercem algum controle sobre o comportamento dos gestores, mas esse controle é, por um lado, limitado aos gestores de carreira, que têm maior custo de oportunidade se perderem seu emprego e, por outro lado, leva-os a uma gestão burocrática. Já os gestores temporários escolherão investir em prol do bem-estar social se do tipo social, ou do benefício pessoal (decisões ilícitas) se do tipo pessoal.

O Caso 2 há um controle ainda maior sobre o comportamento dos gestores, que impede a corrupção. No entanto, esse controle é ineficiente no sentido de que apenas os gestores sociais temporários proverão o máximo de suas capacidades inovadoras em prol da sociedade.

O Caso 3 tem efeito simétrico. Favorece a inovação por parte dos gestores sociais, sejam eles de carreira ou temporários e controla parcialmente os gestores do tipo pessoal, aqueles que pertencem à carreira. No entanto, haverá corrupção por parte dos gestores temporários do tipo pessoal.

O Caso 4 é o caso de instituições fracas em que o que determina a ação do gestor é exclusivamente sua convicção pessoal, de forma que os gestores sociais, sejam eles de carreira ou temporários, inovarão em prol do bem-estar social enquanto os gestores do tipo pessoal, da carreira do serviço público ou fora dela, se corromperão. 
O Caso 5 refere-se a uma situação em que a ação inovadora é estimulada para os gestores sociais, enquanto os gestores do tipo pessoal decidirão adotar postura burocrática, mas não se corrompem. Caso os parâmetros da sociedade correspondam a esse caso, teremos um equilíbrio semelhante àquele que seria obtido se a alteração de não punição de inovações sociais, proposta na seção 4.1, fosse implantada no Caso 1.

Finalmente, o Caso 6 é o caso dramático de instituições extremamente rígidas em que a inação é a decisão tomada por todos os tipos de gestores. Trata-se de situação nefasta à sociedade, pois não há qualquer movimento na direção de maior eficiência da máquina pública. Tal situação é particularmente dramática nas sociedades modernas em que inovações tecnológicas estão constantemente a demandar reações inovadoras dos gestores públicos. Vale notar aqui um possível paralelo entre esta situação institucional e a teoria da corrupção, segundo a qual, conforme citado anteriormente, "em termos de crescimento econômico, a única coisa pior que uma sociedade com uma burocracia rígida, excessivamente centralizada e desonesta, é uma sociedade com uma burocracia rígida, excessivamente centralizada e honesta." ${ }^{21}$

A Tabela A9 sumaria os resultados apresentados na Proposição Al.

Tabela A9 - Incentivos institucionais e comportamento dos gestores públicos

\begin{tabular}{|c|c|c|c|c|c|c|}
\hline \multirow{3}{*}{ Caso } & \multirow{3}{*}{ Incentivos Institucionais } & \multirow{3}{*}{ Descrição } & \multicolumn{4}{|c|}{ Decisão do Gestos } \\
\hline & & & \multicolumn{2}{|c|}{ Gestor de carreira } & \multicolumn{2}{|c|}{ Gestor temporário } \\
\hline & & & Social & Pessoal & Social & Pessoal \\
\hline $\begin{array}{c}1 \\
\text { CII }\end{array}$ & $\begin{array}{l}\pi w_{C}>\alpha_{A} b_{S}-\psi>\pi w_{T} \\
\pi w_{C}>b_{P}-\psi>\pi w_{T}\end{array}$ & $\begin{array}{l}\text { Incentivos } \\
\text { Intermediários }\end{array}$ & $n$ & $n$ & $s$ & $p$ \\
\hline $\begin{array}{c}2 \\
\mathrm{CIF}\end{array}$ & $\begin{array}{l}\pi w_{C}>\alpha_{A} b_{S}-\psi>\pi w_{T} \\
\pi w_{C}>\pi w_{T}>b_{P}-\psi\end{array}$ & $\begin{array}{l}\text { Incentivos } \\
\text { Fortes }\end{array}$ & $n$ & $n$ & $s$ & $n$ \\
\hline $\begin{array}{c}3 \\
\text { Clf }\end{array}$ & $\begin{array}{l}\alpha_{A} b_{S}-\psi>\pi w_{C}>\pi w_{T} \\
\pi w_{C}>b_{P}-\psi>\pi w_{T}\end{array}$ & $\begin{array}{l}\text { Incentivos } \\
\text { Fracos }\end{array}$ & $s$ & $n$ & $s$ & $p$ \\
\hline $\begin{array}{c}4 \\
\mathrm{CIN}\end{array}$ & $\begin{array}{l}\alpha_{A} b_{S}-\psi>\pi w_{C}>\pi w_{T} \\
b_{P}-\psi>\pi w_{C}>\pi w_{T}\end{array}$ & $\begin{array}{l}\text { Incentivos Não } \\
\text { Ativos }\end{array}$ & $s$ & $p$ & $s$ & $p$ \\
\hline $\begin{array}{c}5 \\
\text { CIS }\end{array}$ & $\begin{array}{l}\alpha_{A} b_{S}-\psi>\pi w_{C}>\pi w_{T} \\
\pi w_{C}>\pi w_{T}>b_{P}-\psi\end{array}$ & $\begin{array}{l}\text { Incentivos } \\
\text { Sociais }\end{array}$ & $s$ & $n$ & $s$ & $n$ \\
\hline $\begin{array}{c}6 \\
\mathrm{CIR}\end{array}$ & $\begin{array}{l}\pi w_{C}>\pi w_{T}>\alpha_{A} b_{S}-\psi \\
\pi w_{C}>\pi w_{T}>b_{P}-\psi\end{array}$ & $\begin{array}{l}\text { Incentivos } \\
\text { Rígidos }\end{array}$ & $n$ & $n$ & $n$ & $n$ \\
\hline
\end{tabular}

Fonte: Desenvolvimento dos autores

${ }^{21}$ Huntington (1968). Veja também, a esse respeito, Bugarin e Vieira (2008) ou Bardhan (1997). 